WAPD-TM-1299 DEPARTMENT OF ENERGY RESEARCH AND DEVELOPMENT REPORT

\title{
ANALYSIS OF HOMOGENEOUS U233 AND U235 CRITICAL ASSEMBLIES WITH ENDF/B-IV DATA
}

(AWBA DEVELOPMENT PROGRAM)

OCTOBER 1977

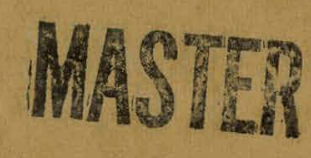

CONTRACT EY-76-C-11-0014 


\section{DISCLAIMER}

This report was prepared as an account of work sponsored by an agency of the United States Government. Neither the United States Government nor any agency Thereof, nor any of their employees, makes any warranty, express or implied, or assumes any legal liability or responsibility for the accuracy, completeness, or usefulness of any information, apparatus, product, or process disclosed, or represents that its use would not infringe privately owned rights. Reference herein to any specific commercial product, process, or service by trade name, trademark, manufacturer, or otherwise does not necessarily constitute or imply its endorsement, recommendation, or favoring by the United States Government or any agency thereof. The views and opinions of authors expressed herein do not necessarily state or reflect those of the United States Government or any agency thereof. 


\section{DISCLAIMER}

Portions of this document may be illegible in electronic image products. Images are produced from the best available original document. 
ANALYSIS OF HOMOGENEOUS U233 AND U235
CRITICAL ASSEMBLIES WITH ENDF/B-IV DATA

(AWBA DEVELOPMENT PROGRAM)

J. J. Ullo

J. Hardy, Jr.

CONTRACT No. EY-76-C-11-0014

OCTOBER 1977

Printed in the United States of America
Avaliable from the

National Technical Information Service

U. S. Department of Commerce 5285 Port Royal Road

Springfield, Virginia 22151

\section{NOTE}

This document is an interim memorandum prepared primarily for Internal reference and does not represent a final expression of the opinion of Westinghouse. When this memorandum is distributed externally, it is with the express understanding that Westinghouse makes no representation as to completeness, accuracy, or usability of information contained therein. 
This report was prepared as an account of work sponsored by the United States Government. Neither the United States, nor the United States Department of Energy, nor any of their employees, nor any of their contractors, subcontractors, or their employees, makes any warranty, expressed or implied, or assumes any legal liability or responsibility for the accuracy, completeness, or usefulness of any information, apparatus, product, or process disclosed, or represents that its use would not infringe privately owned rights. 


\section{FOREWORD}

Subsequent to development and successful operation of the Pressurized Water Reactor in the AEC-owned reactor plant at the Shippingport Atomic Power Station, the Alomic Energy Commission in 1965 undertook a research and development program on a breeder reactor for operation in the Shippingport Station. With tabrication of the Light Water Breeder Reactor (LWBR) nearing completion in 1976, the Energy Research and Development Administration established the Advanced Water Breeder Applications program (AWBA) to develop and disseminate technical information which would assist U.S. industry in evaluating the LWBR concept. All three of these reactor development projects have been administered by the Division of Naval Reactors with the goal of developing practical improvements in the utilization of nurlear finel resources for yuueration of electrical eneroy using water-cooled nuclear reactors.

The Shippingport Atomic Power Station located in Shippingrent, Penz. sylvania was the first large-scale, central-station nuclear power plant in the United States and the first plant of such size in the world operated solely to produce electric power. This project was started in 1953 to confirm the practical application of nuclear power for large-8cale electric power generation. It has provided much of the technology being used for design and operation of the commercial, central-station nuclear power plants now in use.

The objective of the Light Water Breeder Reactor project has been to develop a technology that would significantly improve the utilization of the nation's nuclear fuel resources employing the well-established water reactor technology. To achieve this objective, work has been directed toward analysis, design, component tests, and fabrication of a water-cooled, thorium oxide fuel cycle breeder reactor to install and operate at the Shippinguort Station. Operation of the LWBR core in the Shippingport Station is expected to start in 1977 and be completed in about 3 to 4 yoars. Than the fissionable fucl inventury of the core will be measured. This effort, when completed in about 2 to 3 years after completion of LWBR core operation, is expected to confirm that breeding actually took place.

The Advanced Water Breeder Applications (AWBA) project was initiated to develop and disseminate technical information that will assist U.S. industry in evaluating the LWBR concept for commercial-scale applications. The project will explore some of the problems that would be faced by industry in adapting technology confirmed in the LWBR program. Information to be developed includec concepts fur commercial-scale prebreeder cores which will produce uranium-233 for light water breeder cores while producing electric power, improvements for breeder cores based on the technology developed to fabricate and operate the Shippingport LWBR core, and other information and technology to aid in evaluating commercial-scale application of the LWBR concept.

Technical information developed under the Shippingport, LWBR, and AWBA projects has been and will continue to be published in technical memoranda, one of which is this present report. 
Page No.

ABSTRACT . . . . . . . . . . . . . . . . . . vil

I. INTRODUCTION AND SUMMARY . . . . . . . . . . . . I

II. CALCULATIONAL METHODS. . . . . . . . . . . . 5

III. CRITICALITY VERSUS HYDROGEN/URANIUM RATIO. . . . . . 6

A. ENDF/B-IV Analysis Results ........... 6

B. Sensitivities of Calculated Eigenvalues to

Nuclear Data . . . . . . . . . . . . 19

IV. THERMAL PARAMETER CONSTRAINTS DERIVED FROM THE

GWIN-MAGNUSON CRITICALS. . . . . . . . . . . . . 37

A. PTMG Calculations. . . . . . . . . . . 37

B. Calculated Results ...... . . . . . . . 48

c. Thermal Criticality Parameter Constraint . . . . .56

ACKNOWLEDGMENTS. . . . . . . . . . . . . . . . . . . .

REFERENCES . . . . . . . . . . . . . . . 71

APPENDIX I - Uncertainty of K2 Estimate. . . . . . . . I-I

APPENDIX II - Sensitivity of K2 to $\sigma_{a H}(.0253 \mathrm{eV})$. . . . II-I 
List of Tables

Table No.

Title

Page No.

1

4

Critical Parameters for the Uranium-233 Assemblies

Used for Leakage Studies . . . . . . . . . . 7

Critical Parameters for the Uranium-235 Assemblies

Used for Leakage Studies. . . . . . . . . . . . 9

Resulis of Calculations nf Snmo Highly Inriciled U233 Critical Experiments Using ENDF/B-IV. . . . . . .12

Results of Calculations of Some Hignly Enriched U235 Critical Experiments Using ENDF/B-IV. . . . . . .13

Calculated Leakage Fractions and Fission Ratios

Using ENDF/B-IV. . . . . . . . . . . . . 14

Results of Studies Using Eq. (8) . . . . . . . . 20

Sensitivities of U233 Critical Assemblies to Changes

in Nuclear Data. ............ 26

Sensitivities of y235 Critical Assemulles to Changes

in Nuclear Data. . . . . . . . . . . 27

Sensitivities of Eigenvalues to Uranium Capture and

Fission Resonance Integrals. . . . . . . . . . .35

Uranium Resonance Capture and Fiecion Integrals. . . . 36

Calculated Few Group Radial Leakages and Inferred

Bucklings (Experiment 16).................. 39

Comparison of Galculnted aid Mcasured Radid

Bucklings for Cylinders. . . . . . . . . . . . .42

Comparison of Calculated and Measured Total Bucklings

for Cylinders and Tubs ............. . . 43

Bucklings Inferred from Calculated Leakages for

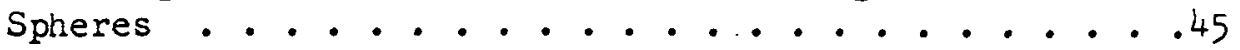

Comparison of Calculated Few Group Axial leakages

at the Core Boundary (Experiment 26) . . . . . . 47

(Continued) 
List of Tables (Cont'd)

Table No.

Title

Page No.

$14 \mathrm{~B}$

Comparison of Calculated Few Group Axial Leakages at a Plane $9.46 \mathrm{~cm}$ from the Core Boundary

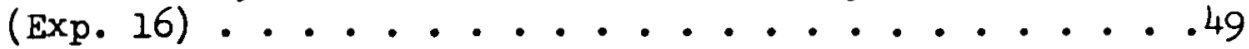

15

Calculated Reaction Rates for U235 Criticals. . . . .50

16

Calculated Reaction Rates for U233 Criticals. . . . . .51

17

Comparison of RCPOI and PTMG Eigenvalue Results . . . . 54

18

Comparison of RCPOI and PTMG Calculated Leakages. . . . 55

19

Additional Calculated Results . . . . . . . . . 60

20

Estimates of $\mathrm{K} 2$ at $\mathrm{FP}=1.0 . . . . . . . . .62$

21

Values of K2 at FP $=1.0$ Derived by Gwin (Ref. 4) with

Measured Bucklings. . . . . . . . . . . . 67

22

Factors Considered in Assigning Uncertainty to K2 . . .68 


\section{List of Figures}

Fig. No.

Title

Page No.

1

2

Eigenvalues of Gwin-Magnuson U233 Criticals as a

Function of Epithermal/Thermal U233 Fission Ratio. . . . 16

$\delta \lambda$ Versus $i n\left(1-L_{F l}\right)$ for the U233 Assemblies

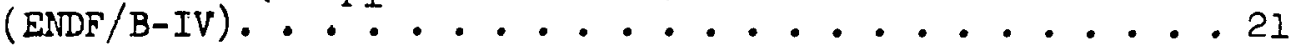

$6 \lambda$ Versus $\ln \left(1-L_{F 1}\right)$ for the $U 23.5$ Assemblies

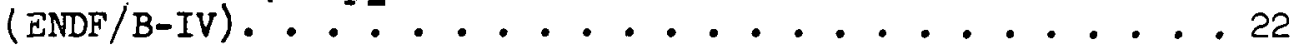

$\delta \lambda$ Versus $k n\left(1-L_{F 2}\right)$ for tine U233 Assemblies

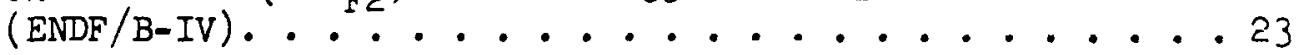

$\delta \lambda$ Versus $i n\left(1-\mathrm{L}_{\mathrm{F} 2}\right)$ for the $\mathrm{U} 235$ Assemblies

(ENDF/B-IV)................. 24

$\Delta \lambda$ Versus Epithermal Neutron Leakage Fraction

$\mathrm{L}_{\mathrm{F}}(>0.625 \mathrm{eV})$ for Various oxygen Changes (U233). . . . 28

$\delta \lambda$ Versus Epithermal Neutron Leakage Fraction

$\mathrm{L}_{\mathrm{H}^{\prime}}(>0.6 \hat{2}$, eV) for Various Uxygen Changes (U235). . . . 29

Sensitivities to Fissinn Snectra Versue Epithermal

Leakage $I_{\mathrm{F}}(>0.625 \mathrm{eV})(\mathrm{IP} 33) \ldots . . . . . . . . .32$

Sensitivities to Fission Spectra Versus Ep1thermal

Leakage $\mathrm{L}_{\mathrm{F}}(>0.625 \mathrm{eV})(\mathrm{U} 235)$. . . . . . . . 33

Few Group Radial Flux Shapes Near the Boundary

(Experiment 16).................... 41

Ratio of Measured to Calculated Buckling İor Gwin-

Magnuson Cylinders . . . . . . . . . . . 44

Few Grnin Axirl Flux Shapec Near the Bunndury

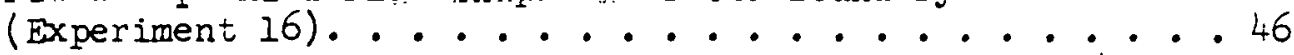

Calculated Eigenvalue Versus Total Leakage Fraction

for U233 Criticals . . . . . . . . . . . . 52

Calculated Eigenvalue Versus Total Leakage Fraction

for 0235 Criticals . . . . . . . . . . . 53

Thermal Criticality Parameter K2 Versus FP, Calculated

with ENDF/B-IV and with Augmented Leakage for UR33

Criticals................ 63

(Continued) 


$$
\text { -vii- }
$$

\section{List of Figures (Cont'd)}

Fig. No.

Title

Page No.

Thermal Criticality Parameter K2 Versus FP Calculated with ENDF/B-IV for U235 Criticals ....... . 64 


\section{ABSTRACT}

Thirty-two U233 and U235 homogeneous aqueous critical experiments were analyzed with ENDF/B-IV data. Calculated eigenvalues for both fuel types increased by nearly $2 \%$ nver the range of hydrogen/uralliul abumic ratin covered (t'rom '2106-27.1). This is attributed mostly to an underprediction of Iats leakrage, with some contribution from the fission and capture resonance integrals of ENDF/B-IV U235. Eigenvalue sensitivities to several nuclear data changes were examined. Values of the thermal criticality parameter constraint K2 for U233 and U235 were derived from the Gwin-Magnuson critical experiments at the zero leakage limit. $\mathrm{K} 2 \equiv\left(\bar{\eta}_{\mathrm{U}}-1\right) \bar{\sigma}_{\mathrm{QU}} / \bar{\sigma}_{\mathrm{aH}}$ relates the thermal-average eta for uranium and the uranium and hydrogen absorption cross sections. 
ANALYSIS OF HOMOGENEOUS U233 AND U235

CRITICAL ASSEMBLIES WITH ENDF/B-IV DATA

(AWBA Development Program)

$$
\begin{aligned}
& \text { J. J. Ullo } \\
& \text { J. Hardy, Jr. }
\end{aligned}
$$

\section{INTRODUCTION AND SUMMARY}

Thirty-two U233 and U235 homogeneous aqueous critical experiments have been analyzed with ENDF/B-IV data. The critical eigenvalue $\left(\mathrm{K}_{\text {eff }}\right)$ and detailed reaction rates were calculated for each experiment. This study had two princ1pal aims:

1) To examine the ability of these data to predict the criticality of systems covering a wide range of hydrogen/uranium atom ratios $(\mathrm{H} / \mathrm{U})$. The range of $\mathrm{H} / \mathrm{U}$ was 119.4 - 2106 for U233 and 27.1 - 2052 for U235, with a correspondingly wide range of spectrum hardness and of leakage (from 1\% - 50\%). This work was prompted by a study done at oak Ridge by McNeany and Jenkins (Ref. I) to compare Hanson-Roach and ENDF/B-IV cross sections. They reported errors of several percent in calculated neutron multiplication factors for homogeneous U233 assemblies with low $\mathrm{H} / \mathrm{U}$ ratios when $\mathrm{ENDF} / \mathrm{B}-\mathrm{IV}$ data were used. It was concluded in Ref. I that the ENDF/B-IV data file was not satisfactory for criticality calculations of such assemblies.

We have analyzed a set of eight U233 criticals (including several of those considered in the oak Ridge study) and a corresponding set of U235 systems for comparison. In addition, eigenvalue sensitivities to certain data changes have been determined. These changes include the ENDF/B version of the oxygen cross sections, the mean energies and shapes of the fission neutron spectra, the hydrogen thermal absorption cross section, the uranium capture and fission resonance integrals, and the uranium inelastic cross sections. 


\section{$-2-$}

2) To determine the implications for the thermal criticality parameters of U233 and U235 which can be derived from the 23 Gwin-Magnuson critical spheres and cylinders (Ref. 2). This is an extension of

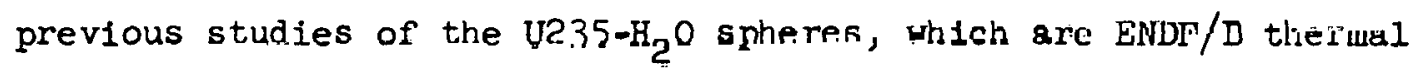
reaclur benchmarks (Kef. 3), to emphasize low-leakage systems. It follows the methodology presented recently by Gwin (Ref. 4) who has emphasized the importance of minimizing the effects of leakage in evaluating these experiments.

The principal results of this study are summarized as follows:

1. Eigenvalues for critical U233 and U235 systems, calculated with ENDF/B-IV data, show an upward trend of approximately $2 \%$ with decreasing $\mathrm{H} / \mathrm{U}$. Similar results were previsusly rcported in Re $\int .9$.

2. Criticality of the U233 systems agrees well with the results of similar studies at ORNL.

3. U233 and U235 systems show the same eigenvalue trend, wish appers to ve lue mostly to an underprediction of fast leakage. The best-fit elgenvalues are:

$\begin{array}{lll}\text { Total Leakage: } & 0 & 50 \% \\ \text { U233 } \lambda: & .996 & 1.015 \\ \text { U235 } \lambda: & .994 & 1.012\end{array}$

4. The most likely sources of leakage error appear to be the U233 and U235 fission spectra (mean energy and shape), and the oxygen scattering cross sections and angular patterns in the MeV range. For U235, 
the resonance capture and fission integrals are significant for the eigenvalue trend.

5. The calculated eigenvalues of high leakage assemblies are reduced approximately $0.6 \%$ by use of ENDF/B-I oxygen, with negligible effect on large assemblies. The Version III oxygen shows an intermediate behavior.

6. Sensitivity to the fission spectrum mean energy (at $\sim 50 \%$ leakage) is

$$
\partial \lambda / \partial \bar{E}_{f} \sim-.15 / \mathrm{MeV}
$$

For a mean energy of $\overline{\mathrm{E}}_{\mathrm{f}}=2.00 \mathrm{MeV}$, the Watt shape reduces small-core eigenvalues by $0.3-0.4 \%$ compared to a Maxwellian. It is difficult to account entirely for the reactivity drift by credible hardening of the fission spectra for U233 and U235.

7. The small U235 cores are significantly sensitive to the capture and fission resonance integrals of U235. Approximately $0.5 \%$ of the elgenvalue trend can be attributed to the high fission integral, and the low capture integral, of ENDF/B-IV Mat. 1261. Improved resonance integrals for U235 along with a hardened Watt fission spectrum $(\bar{E}=2.016$ MeV) can eliminate most of the eigenvalue trend for U235 sys tems. 
8. The reduction of the hydrogen thermal absorption cross section by $0.002 b$ (to $0.330 b$ ) has little effect on high leakage assemblies but increases the calculated eigenvaluco for theswal assembilies by $0.3 \%$.

9. There is negligible sensitivity to inelastir scattering cross sections of 1233 and U23.

10. The Gwin-Magnuson criticals at the zero leakage limit determine a constraint $\mathrm{K} 2$ on the uranium thermal criticality parameters. $K 2=\left(\bar{\eta}_{x}-1\right) \bar{\sigma}_{a x} \sqrt{\sigma}_{a H}$ involves the thermal spectrum average $(0-.625 \mathrm{eV})$ eta for uranium, and the uranium and hydrogen absorption cross sections. The following values were obtained from the present. analyses:

$$
\begin{aligned}
& K 2=2240 \pm 11 \\
& K 2=2155 \pm 11
\end{aligned}
$$

Tue presimed leakage underprediction of FiNDF/B-IV does not significantly affect these results. The three U2 35 tubs have been omitt.en; their incluoion ruuld raise ki for U235 by $0.26 \%$. This is considered to be the largest single question of interpretation of these experiments. 


\section{CALCULATIONAL METHODS}

Nuclear data were from ENDF/B-IV, multigroup processed with the ET $\phi$ MX

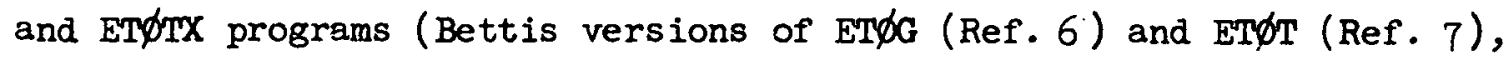
respectively). A detalled fission-source-in- $\mathrm{H}_{2} \mathrm{O}$ weighting spectrum was used in the multigroup averaging. Thermal scattering kernels were generated with FLAR2 (a Bettis version of FLANGEII (Ref. 8)) from the ENDF/B $S(\alpha, \beta)$ files based on the Haywood kernel.

The criticals were analyzed with the Monte Carlo program RCPOl, an extension of RECAP (Ref. 9), and with PTMG, an extension of P3MG (Ref. 10), a one-dimensional, multigroup $P_{\ell}$ program. RCPOl was used for the overall study of criticality versus $\mathrm{H} / \mathrm{U}$ ratio. Cross section sensitivities were derived from PTMG, which was also used for the analysis of the Gwin-Magnuson criticals to infer constraints on the $2200 \mathrm{~m} / \mathrm{s}$ parameters for U233 and U235. The agreement between RCPOI and PTMG was checked for five specific experiments and found to be very good,

RCPOI represented the geometry explicitly. It used detailed Doppler broadened resonance profiles over the ENDF/B resolved and unresolved resonance ranges (typically $-25,000$ energies). In addition, there were multigroup cross sections, following the MUFT 54 group scheme, for inelastic group transfer (including $n, 2 n$ multiplication). The elastic scattering angular distribution was described by a $\mathrm{P}_{3}$ approximation in each multigroup. In the thermal energy range $(0-0.625 \mathrm{eV})$, cross sections were described at 25 energies, including $\mathrm{P}_{3}$ transfer matrices for hydrogen bound in $\mathrm{H}_{2} \mathrm{O}$. The small fraction of the fission source above $10 \mathrm{MeV}$ was folded into the first MUT group, and the hydrogen scattering cross section in this group was averaged accordingly. 
PTMG calculations were similar to the original analyses of Staub, et al. (Ref. 11). There were 57 fast groups (the MUFT 54 group scheme with three additional $\Delta u=0.25$ groups above $10 \mathrm{MeV}$ ). There was one thermal group ( 0 $0.625 \mathrm{ev}$ ) with cross sections averaged in a 25 -group infinite medium calculation. The flux angular treatment was double- $P_{1}$ thermally and $P_{T}$ fast (with $n$ simplified $\mathrm{P}_{7}$ treatment used for spheres and cylinders). Marshak boundary conditions were used.

\section{CRITICALITY VERSUS HYDROGEN/URANIUM RATIO}

\section{A. ENDF/B-IV Analys is Results}

Eight U233 and nine U235 critical assemblies were analyzed in this part of the study. They are sumarized in Tables 1 and 2 along with references to the original documentation.

These assemblies were spheres and cyllnders containing aqueous solutions of uranyl nitrate or uranyl finoride. They were bare, except for expexlment L7, which had an essentially infinite water reflector. The range of $\mathrm{H} / \mathrm{U}$ was 27.1 - 2052 for 0235 and 119.4 - 2106 for U233. Leakage ranged up to about $50 \%$.

In some cases the documentation of the experiments is limited. What are believed to be the best data describing the measurements are given in Tables 1 and 2. For a few cases the data have not been corrected for the effects of the vessel walls. Where sufficient information was available the vessels were included in the calculation. Generally, however, the effects of the vessel walls on unreflected assemblies are judged to be quite small.

The U233 results (Table 3) show generally good agreement with the oak Ridge calculations. This suggests that, for this specific case, the use of different analysis programs and nuclear data processing procedures has little effect on the calculated results. 
TABLE 1

\section{Critical Parameters for the Uranium-233 Assemblies Used for Leakage Studies}

\section{Experiment $^{\dagger}$}

L1. Unreflected cylinter of aqueous $\mathrm{UO}_{2}\left(\mathrm{NO}_{3}\right)_{2}$ solution (Ref. 12$)$.

L2. Unreflected cylinder of aqueous $\mathrm{UO}_{2} \mathrm{~F}_{2}$ solution (Ref. 13).

L3. Unre:lected sphere of aqueous $\mathrm{UO}_{2} \mathrm{~F}_{2}$ solution (Ref. 13).

L4. Unreflected sphere of. acueous $\mathrm{UO}_{2}\left(\mathrm{NO}_{3}\right)_{2}$ solution (Ref. 12).

9. Unreflected sphere of aqueous $\mathrm{UO}_{2}\left(\mathrm{NO}_{3}\right)_{2}$ solution (Ref. 2 ).

5. Unreflected sphere of aqueous $\mathrm{UCh}\left(\mathrm{NO}_{3}\right)_{2}$ solution (Ref. 2 )

11. Unreflected sphere of aqueous $\mathrm{VO}_{2}\left(\mathrm{NO}_{3}\right)_{2}$ solution (Ref. 2 )
Critical. Height

$(\mathrm{H}=\mathrm{cm})$ and/or

$\mathrm{H} / \mathrm{U} 33$ Rajius $(\mathrm{R}=\mathrm{cm})$

$119.4 \quad \mathrm{H}=24.69$

$\mathrm{R}=12.70$

154

$\mathrm{H}=24.0+0.05 *$

$R=12.75$

381.

$R=15 \cdot 94$

16.965

1.14

$581 \quad R=18.378$

26.0

1.16

$1324 \quad R=34.5948$

173.43

$3 \cdot 36$

$1533 R=34.5948$

173.43

2.90

$1986 \quad R=61.0108$

$951 \cdot 3$

12.32
Comment

Aluminum walls, endplate, and fillpipe included in the calculation.

Calculated as a bare assembly. Not reported whether data was corrected for the effects of the aluminum vessiel.

Same as for experiment No. 2 .

Calculated as a bare assembly.

Calculated as a bare assembly. Boron content $0.0912 \mathrm{mg} / \mathrm{cm}^{3}$.

Calculated as a bare assembly.

Calculated as a bare assembly. 
TABLE 1 (Cont'd)

Experiment

20. Unreflected cylinder of aqueous $\mathrm{UO}_{2}\left(\mathrm{NO}_{3}\right)_{2}$ solution (Ref. 2 )
Critical Heignt.

$(\mathrm{H}=\mathrm{cm})$ and/or

H/U233

2106

Fadius ( $\mathrm{R}=\mathrm{cm}$ )

$\mathrm{H}=140.1572$

$R=77.3684$

Critical

Volume

(Liters)

2635.68

2.77 .3684$.

\section{Critical \\ Mass of $\mathrm{J} 233$ \\ $(\mathrm{Kg})$}

33.04
Comment

Critical height included correction for 0.53 in. bottom $\varepsilon$ tructure. Calculated as a tare assembly.

\footnotetext{
*Extrapolated values based on source zeutron multzilication curves.

'I.D.'s of the Gwin-Magnusol. experiments are the sane as in Reference 2. Other critical experiments are denoted LI-L9.
} 


\section{TABIL 2}

Critical Parameters for the Uranium-235 Assemblies Used for Leakage Studies

\section{Experiment}

L5. Unreflected cylinder of aqueous $\mathrm{UO}_{2} \mathrm{~F}_{2}$ solution (Ref. 14).

I6. Unreflected cylinder of aqueous $\mathrm{VO}_{2} \mathrm{~F}_{2}$ solution (Ref. 14).2

L7. Reflected sphere of aqueous $\mathrm{UO}_{2} \mathrm{~F}_{2}$ solution (Ref. 15).

L8. Unreflected sphere of aqueous $\mathrm{UO}_{2} \mathrm{~F}_{2}$ solution (Ref. 15).

2. Unreflected 8 phere of aqueous $\mathrm{UO}_{2}\left(\mathrm{NO}_{3}\right)_{2}$ solution (Ref. 2 ).

L9. Unreflected sphere of aqueous $\mathrm{UO}_{2} \mathrm{~F}_{2}$ solution (Ref. 15).

10. Unreflected sphere of aqueous $\mathrm{UO}_{2}\left(\mathrm{MO}_{3}\right)_{2}$ solution (Ref. 2 ).

16. Unreflected cylinder of aqueous $\mathrm{VO}_{2}\left(\mathrm{NO}_{3}\right)_{2}$ solution (Ref.2).

H/U235 $\begin{gathered}\text { Critical Helght } \\ \text { (H=cm) and/or } \\ \text { Radius ( } \mathrm{R}=\mathrm{cm})\end{gathered}$

27.1

$\mathrm{H}=38.9$

$\mathrm{R}=12.7$

$44.3 \quad \mathrm{H}=35.1$

$76.1 \quad R=11.5$

1112

$R=27.9$

91.1

2.13

1117

$R=34.5948$

173.43

3.80

1393

$R=34.6$

174.0

3.25

1835

$R=61.0108$

951.3

13.43

1981

$\mathrm{H}=204.9272$

$R=77.3684$

$3853.69 \quad 54.19$

Comment

Data reported to be corrected for aluminum baseplate and vessel walls. Calculated as a bare assembly.

Same as experiment No. 1.

Calculations included the 1.6 mm-thick aluminum vessel.

Calculations included $2.0 \mathrm{mrn}-$ thick aluminum vessel.

Calculated as a bare assembly. Boron content $0.0935 \mathrm{mg} / \mathrm{cm}^{3}$.

Calculstions included $3.2 \mathrm{~mm}-$ thick aluminum wall.

Calculated as a bare assembly.

(Continued)
Critical height included correction for 0.53-in. bottom structure. Calculated as a bare assembly. 
TABLE 2 (Cont'd)

\begin{tabular}{|c|c|c|c|c|c|c|}
\hline & Experiment ${ }^{*}$ & B/U23. & $\begin{array}{l}\text { Critical Height } \\
\text { ( } \mathrm{H}=\mathrm{cm}) \text { End/or } \\
\text { Radius ( } \mathrm{R}=\mathrm{cm}) \\
\end{array}$ & $\begin{array}{l}\text { Critical } \\
\text { Volume } \\
\text { (Liters) } \\
\end{array}$ & $\begin{array}{l}\text { Critical } \\
\text { Mass of } \mathrm{J} 235 \\
(\mathrm{Kg}) \\
\end{array}$ & Comment \\
\hline 23. & $\begin{array}{l}\text { Unreflected cylinder of } \\
\text { aqueous } \mathrm{UO}_{2}\left(\mathrm{NO}_{3}\right)_{2} \text { solu- } \\
\text { tion (Ref. } 2) .\end{array}$ & 2052 & $\begin{array}{l}H=241 \cdot C=6 \\
R=136.779\end{array}$ & 14167.35 & 192.82 & $\begin{array}{l}\text { No correction was made ex- } \\
\text { perimentally for the effects } \\
\text { Jf structure. Calculated as } \\
\text { a base assembly. }\end{array}$ \\
\hline
\end{tabular}

\footnotetext{
I.D.'s of the Gwin-Magnuson experiments are the same as in Reference 2. Other critical experiments are denoted LI-L9.
} 
One assembly (with a thick paraffin reflector) analyzed in Ref. 1 has not been included in Table 1. However, our calculation, which was hampered by lack of a sultable thermal scattering kernel for paraffin, showed a bias of $+6.5 \%$ in good agreement with the ORNL value of $+7 \%$. This is grossiy out of line with results for the other critical assemblies, probably due to difficulty of interpreting the paraffin reflector.

For both U233 and U235, the ENDF/B-IV-calculated eigenvalues (Tables 3 and 4) become Increasingly high relative to experiment as the $H / U$ ratio is decreased from well thermalized systems.

Along with the decrease of $\mathrm{H} / \mathrm{U}$ there is an assoclated increase of leakage and a hardening of the flux spectrum. This is summarized quantitatively in Table 5 where calculated leakage fractions and the ratios of ep1thermal to thermal fissions $(\delta)$ are listed. Corresponding to the increase in $\sigma$ there is an increase in the total and fast neutron leakage fractions.

Since the trend in calculated eigenvalue errors is nearly the same for U233 and U235 systems, it is tempting to seek a common source of difficulty (e.g., oxygen scattering cross section), but this is by no means the only possibility. The following items could be signiflcant:

1) oxygen scattering cross section and angular pattern ( $\mathrm{MeV}$ range)

2) fission spectrum of U233 and of U235

3) uranium capture and fission resonance integrals, and

4) multigroup averaging and limited $\mathrm{P}_{\ell}$ treatment in RCPOl.

It seems unlikely that the trend is due to energy dependent errors of $\eta$ in the thermal range. (which are emphasized as the flux spectrum hardens) since both fuels show nearly the same behavior, and substantial errors would be required. Although there remain questions of interpretation about individual 
TABLE 3

Results of Calculations of Some Highly Enriched U233 Critical Experiments Using ENDF/B-IV

\begin{tabular}{|c|c|c|c|}
\hline \multirow[b]{2}{*}{ Experiment } & \multirow[b]{2}{*}{ H/U233 } & \multicolumn{2}{|c|}{ Calculated $\lambda$} \\
\hline & & Present Work ${ }^{\mathrm{a}}$ & $\begin{array}{l}\text { Oak Ridge } b, c \\
\text { Calculations }\end{array}$ \\
\hline LI & 119.4 & $1.0116 \pm 0.0034$ & $\cdots$ \\
\hline L2 & 1.54 & $1.0226 \pm 0.0027$ & $1.022 \pm 0.007$ \\
\hline $\mathrm{L3}$ & 381 & $1.010 \pm 0.0035$ & $1.007 \div 0.006$ \\
\hline 24 & 581 & $1.0111 \pm 0.0034$ & -- \\
\hline 9 & 1324 & $1.0007 \pm 0.0037$ & -- \\
\hline 5 & 1533 & $1.0017 \pm 0.0016$ & $0.998 \pm 0.004$ \\
\hline 11 & 1986 & $0.9974 \pm 0.0031$ & 0.991 \\
\hline 20 & 2106 & $0.9956 \pm 0.0008$ & - \\
\hline
\end{tabular}

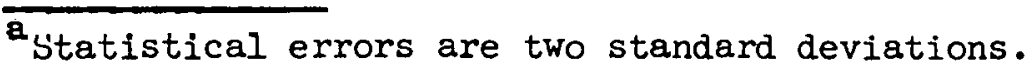

${ }^{b}$ Statistical errors are one standard deviation.

${ }^{c}$ These results have been updated from the results reported in Het. 1.
} 


\section{TABLE 4}

Results of Calculations of Some Highly Enriched U235 Critical Experiments Using ENDF/B-IV

Experiment

I5

16

LT

L8

2

L9

10

16

23
H/U235

27.1

44.3

76.1

1112

1177

1393

1835

1981

2052
Calculated $\lambda^{\mathrm{a}}$

$1.0085 \pm 0.0036$

$1.0117 \pm 0.0030$

$1.0098 \pm 0.0051$

$1.0085 \pm 0.0037$

$1.0007 \pm 0.0035$

$1.0035 \pm 0.0035^{b}$

$0.9936 \pm 0.0031$

$0.9939 \pm 0.0008$

$0.9949 \pm 0.0003$

a

Statistical errors are two standard deviations.

bitie corresponding result for this experiment In-Ref. (I) was $1.006 \pm 0.004(10)$ 


\section{TABLE 5}

Calculated Leakage Fractions and Fission Ratios Using ENDF'B-IV

\begin{tabular}{|c|c|c|c|c|c|c|c|}
\hline$\frac{\text { Experiment }}{\text { IR33 Expert }}$ & $\frac{\mathrm{H} / \mathrm{U}}{\text { ents }}$ & $\begin{array}{l}\text { Total Leakage } \\
\text { Fraction (L) }\end{array}$ & $\begin{array}{l}\text { Leakage to } \\
5.53 \mathrm{keV}\left(\mathrm{L}_{\mathrm{FI}}\right)\end{array}$ & $\ln \left(1-I_{F 1}\right)$ & $\begin{array}{l}\text { Leakage to } \\
0.625 \mathrm{ev}\left(\mathrm{L}_{\mathrm{F} 2}\right) \\
\end{array}$ & $\ln _{n}\left(1-L_{F 2}\right)$ & $\delta^{a}$ \\
\hline 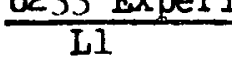 & $\frac{119.4}{119}$ & 0.5149 & 0.3944 & -0.5015 & 0.4912 & -0.6757 & 0.4493 \\
\hline L2 & 154 & 0.5081 & 0.3855 & -0.4869 & 0.4797 & -0.6537 & 0.3466 \\
\hline L3 & 381 & 0.4617 & 0.3316 & -0.4029 & 0.4164 & -0.5385 & 0.1526 \\
\hline 24 & 581 & 0.4081 & 0.2823 & -0.3317 & 0.3562 & -0.4404 & 0.1094 \\
\hline 9 & 1324 & $0.174 \varepsilon$ & 0.1109 & -0.1175 & 0.1413 & -0.1529 & 0.0635 \\
\hline 5 & 1533 & 0.1776 & 0.1104 & -0.1170 & 0.1414 & -0.1524 & 0.0548 \\
\hline 11 & 1986 & $0.068 z$ & 0.0402 & -0.0421 & 0.0520 & -0.0540 & 0.0463 \\
\hline 20 & 2106 & 0.0402 & 0.0238 & -0.0241 & 0.0305 & -0.0310 & 0.0461 \\
\hline \multicolumn{8}{|c|}{ Ue35 Experiments } \\
\hline L5 & 27.1 & 0.4380 & 0.3562 & -0.4404 & 0.4312 & -0.5642 & 0.8175 \\
\hline 16 & 44.3 & 0.4501 & 0.3566 & -0.4410 & 0.4384 & -0.5771 & 0.4722 \\
\hline L7 & 76.1 & 0.4661 & 0.4977 & -0.6886 & 0.5534 & -0.8061 & 0.1962 \\
\hline $\mathrm{L} 8$ & 1112 & 0.2333 & 0.1490 & -0.1613 & 0.1921 & -0.2133 & 0.0251 \\
\hline 2 & 1177 & 0.1678 & 0.1076 & -0.1138 & $0.138 \equiv$ & -0.1488 & 0.0255 \\
\hline L9 & 1393 & 0.1703 & 0.1055 & -0.1115 & 0.1365 & -0.1468 & 0.0214 \\
\hline 10 & 1835 & 0.0663 & 0.0402 & -0.0410 & $0.051 \pi$ & -0.0531 & 0.0179 \\
\hline 16 & 1981 & 0.0329 & 0.2198 & -0.0200 & 0.0256 & -0.0259 & 0.0169 \\
\hline 23 & 2052 & 0.0141 & 0.0084 & -0.0084 & 0.0109 & -0.0118 & 0.0165 \\
\hline
\end{tabular}

\footnotetext{
Ratio of epithermal $(>0.625 \mathrm{ev})$ to thermal $(<0.625 \mathrm{eV})$ fissions.
} 
experiments, this is judged not to be significant for the overall pattern.

Furthermore, calculational approximations (including data processing) are thought to be relatively unimportant. This is supported by the good agreement obtained with the Oak Ridge Analysis (Ref. 1) and also by a comparison of RCPOl-calculated leakage with results obtained by $\mathrm{H}$. H. Henryson II at the Argonne National Laboratory with the VIM Monte Carlo Program (Ref. 16). VIM employed a strictly pointwise representation of the data and a detailed elastic scattering angular treatment (20 equal $\cos \theta$ intervals). The comparison was made for a small cylinder of $\mathrm{U}^{2} 35-\mathrm{H}_{2} \mathrm{O}$ in vacuum, with a spatially flat fission source. ENDF/B-IV data were used. Results for total leakage (10 MeV - $1.12 \mathrm{eV}$ ) were:

$$
\begin{aligned}
\text { RCPOI: } & 0.5285 \pm 0.0006 \\
\text { VIM: } & 0.5267 \pm 0.0007 \\
\hline \text { RCPOI-VIM: } & 0.0018 \pm 0.0009
\end{aligned}
$$

Agreement is very good within statistics (one standard deviation) and, if anything, RCPOl produces slightly more leakage than VIM.

That the criticality bias is not attributable to spectrum hardening alone can perhaps be inferred from the Gwin-Magnuson U233 criticals. (The considerably larger scatter of $\lambda$ for the corresponding U235 systems obscures the argument in that case). Figure 1 shows $\lambda$ for these systems plotted against $\delta^{23}$, the ratio of epithermal-to-thermal U233 fissions. The argument is simply this: If the bias drift in Figure 1 for the unpoisoned cores is attributed to the spectrum hardening which accompanies increased leakage, then additional hardening obtained solely by boron poisoning should continue the trend, but this does not occur. Although the range of hardening is quite limited, this argument at least suggests that the more likely source of difficulty is leakage 1tself (compare also Figure 13). For U235, however, there is some sensitivity to the capture and fission resonance integrals (see the following section). 


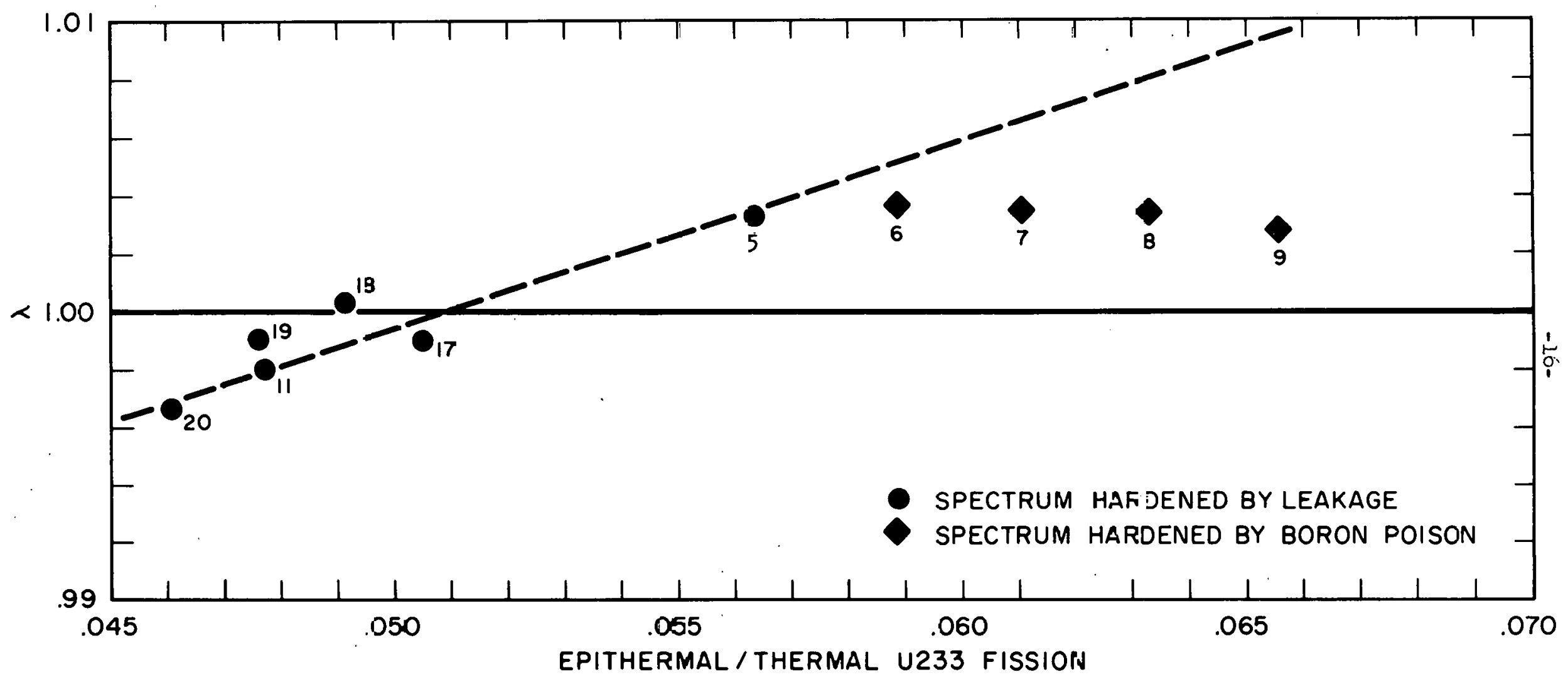

Eigenvalues of Cwin-Magnuson U233 Criticals as a

Function of Epithermal, Thermal U233 Fission Ratio

FIGIJRE 1 
The effect of a leakage underprediction on criticality (items $1-4$ above) can be characterized by means of the critical equation,

$$
\lambda=K_{\infty} \frac{K\left(B, E_{c}\right)}{1+B^{2} L_{T}^{2}},
$$

where

$$
\begin{aligned}
& \lambda \text { is the effective neutron multiplication factor (eigenvalue) } \\
& B \text { is the buckling } \\
& \mathrm{L}_{\mathrm{T}} \text { is the thermal diffusion length } \\
& \mathrm{K}\left(\mathrm{B}, \mathrm{E}_{\mathrm{c}}\right) \text { is the nonleakage probability during slowing down to energy } \mathrm{E}_{\mathrm{c}} \\
& \mathrm{K}_{\infty} \text { is the infinite medium multiplication factor. }
\end{aligned}
$$

$$
\begin{aligned}
K\left(B, E_{C}\right) & =K\left(0, E_{c}\right)+\left.\frac{1}{2} B^{2} \frac{\partial^{2} K\left(B, E_{c}\right)}{\partial B^{2}}\right|_{B=0}+\ldots \\
& =K\left(0, E_{c}\right)\left(1+\frac{1}{2} \frac{\left.\left.B^{2} \frac{\partial^{2} K\left(B, E_{c}\right)}{K\left(0, E_{c}\right)}\right|_{B=0}+\ldots\right)}{\partial B^{2}}\right. \\
& =\left(1-B^{2} L^{2}\left(E_{c}\right)\right) \sim e^{-B_{L}^{2}{ }^{2}\left(E_{c}\right)}
\end{aligned}
$$

where

$$
L^{2}\left(B_{c}\right)=-\left.\frac{\partial^{2} K\left(B, E_{c}\right)}{d B^{2}}\right|_{B=0}
$$


$L\left(E_{c}\right)$ is the slowing down length from fission neutron energies to energy $E_{c}$. Equation ( 1 ) can now be written in the "Fermi-age form,"

$$
\lambda=\frac{K_{\infty} e^{-B^{2} L^{2}\left(E_{c}\right)}}{I+B^{2} L_{T}^{2}}
$$

It is possible starting from Eqn. (6) to deduce a simple lngarithmis relation between the calculated reactivity bias $\delta \lambda$ and the fast neutron leakage fraction $L_{F}$ if an error is introduced into the square of the slowing down length. Differentiation of Egn. (6) with respect to $L^{2}\left(E_{c}\right)$ yields

$$
\frac{\delta \lambda}{\lambda}=\frac{\delta L^{2}\left(E_{c}\right)}{L^{2}\left(E_{c}\right)} \ln \left(1-L_{F}\left(E_{c}\right)\right)
$$

where $L_{F}\left(E_{c}\right)$ is the calculated leakage of all neutrons with energies above a cutoff energy, $E_{c}$. If the relative error in the square of the slowing down length is assumed to be nearly constant for the assimhlips sturied in this work, then a linear relation between $8 \lambda$ and $i_{n}\left(1-L_{r}\left(E_{r}\right)\right)$ is suggested by Eq. (7):

$$
\delta \lambda=a+b \alpha_{n}\left(1-L_{F}\left(E_{c}\right)\right)
$$

where $b=\frac{\delta L^{2}\left(E_{c}\right)}{L^{2}\left(E_{c}\right)}$ is the relative error in the square of the slowing down length to the cutoff energy $E_{c}$. The constant $a$ is included since it is possible that all the calculated results could deviate from unity by a 
practically constant value due to error in the assumed number of neutrons produced per fission.

With the calculated leakage fractions (Pable 5) to cutoff energies of $E_{c}=5.53 \mathrm{keV}\left(L_{\mathrm{Fl}}\right)$ and $E_{c}=0.625 \mathrm{eV}\left(\mathrm{L}_{\mathrm{F} 2}\right)$, weighted least-squares analyses were made using Eqn. (8) (Figs. 2-5). The results for the fitted constants $\mathrm{a}$ and $\mathrm{b}$ are summarized in Table 6 . Within statistics the trend in calculated eigenvalues is independent of fuel type. Since Eqn. (6) and Eqn. (8) are valid only for large thermal assemblies with small fast neutron leakage fractions, for those fits including all the assemblies of a given fuel type the interpretation of the parameter $b$ may be questionable. When fits using Eqn. (8) are made including only the thermal assemblies, the values obtained for $b$ are again similar for both fuels and more indicative of the relative error in the square of the slowing down length. The fit of the calculated U235 results using Eqn: (8) is improved (Table 6) if experiment No. $\mathrm{L} 8(\mathrm{H} / \mathrm{U}=1112$ ) is excluded. Why the calculation of this experiment is out of line with the others could not be determined, but the origin of the discrepancy is thought to be experimental.

B. Sensitivities of Calculated Eigenvalues to Nuclear Data Sensitivities of the calculated eigenvalues to several nuclear data changes were determined for selected U233 and U235 critical assemblies with a wide range of leakage. These changes include the ENDF/B version of the oxygen croes sections, the hydrngen thermal absorption cross section, the uranium capture and fission resonance integrals, the uranium inelastic cross sections, and representations of the fission neutron spectra. 
TABLE 6

Results of Studies Using Eq. (8)

$$
\begin{aligned}
& \frac{\text { Correlation }}{\delta K_{e f f}=a+b \ln \left(1-L_{F l}\right)} \\
& \delta K_{e f f}=a+b \ln \left(1-L_{F l}\right) * \\
& \delta K_{e f f}=a+b \ln \left(1-I_{F 2}\right) \\
& \delta K_{\text {eff }}=a+b \ln \left(1-I_{F_{F}}\right) * \\
& \delta K_{\text {eff }}=a+b \ln \left(1-I_{F I}\right) * *
\end{aligned}
$$$$
\delta K_{\text {eff }}=a+b \alpha_{n}\left(1-L_{F l}\right)
$$$$
6 \mathrm{~K}_{\text {eff }}=\mathrm{a}+\mathrm{b} \ln \left(1-\mathrm{L}_{\mathrm{F} 2}\right)
$$$$
\delta \mathrm{K}_{\text {eff }}=\mathrm{a}+\mathrm{b} \ln \left(1-\mathrm{L}_{\mathrm{Fl}}\right) * * *
$$

\begin{tabular}{ll}
\hline$\frac{\mathrm{at}}{\mathrm{U}-235 \text { Assemblies }}$ \\
\hline$-0.007 \pm 0.002$ & $-0.037 \pm 0.017$ \\
$-0.007 \pm 0.002$ & $-0.036 \pm 0.013$ \\
$-0.007 \pm 0.002$ & $-0.030 \pm 0.012$ \\
$-0.007 \pm 0.002$ & $-0.029 \pm 0.010$ \\
$-0.007 \pm 0.002$ & $-0.07 t \pm 0.037$
\end{tabular}

$\begin{array}{ll}\frac{\mathrm{a} f}{\mathrm{a} f 233 \text { Assemblies }} \\ \frac{\mathrm{b} t}{-0.005 \pm 0.002} & -0.048 \pm 0.011 \\ -0.005 \pm 0.002 & -0.035 \pm 0.009 \\ -0.006 \pm 0.001 & -0.064 \pm 0.008\end{array}$

\footnotetext{
Did not include experiment L8 (H/U $=1112)$.

Included only the five thermal assemblies $(H / U=1177-2052)$. *** Included only the four thermal assemblies (H/U $=1324-2106)$.

'All uncertainties are one standard deviation.
} 


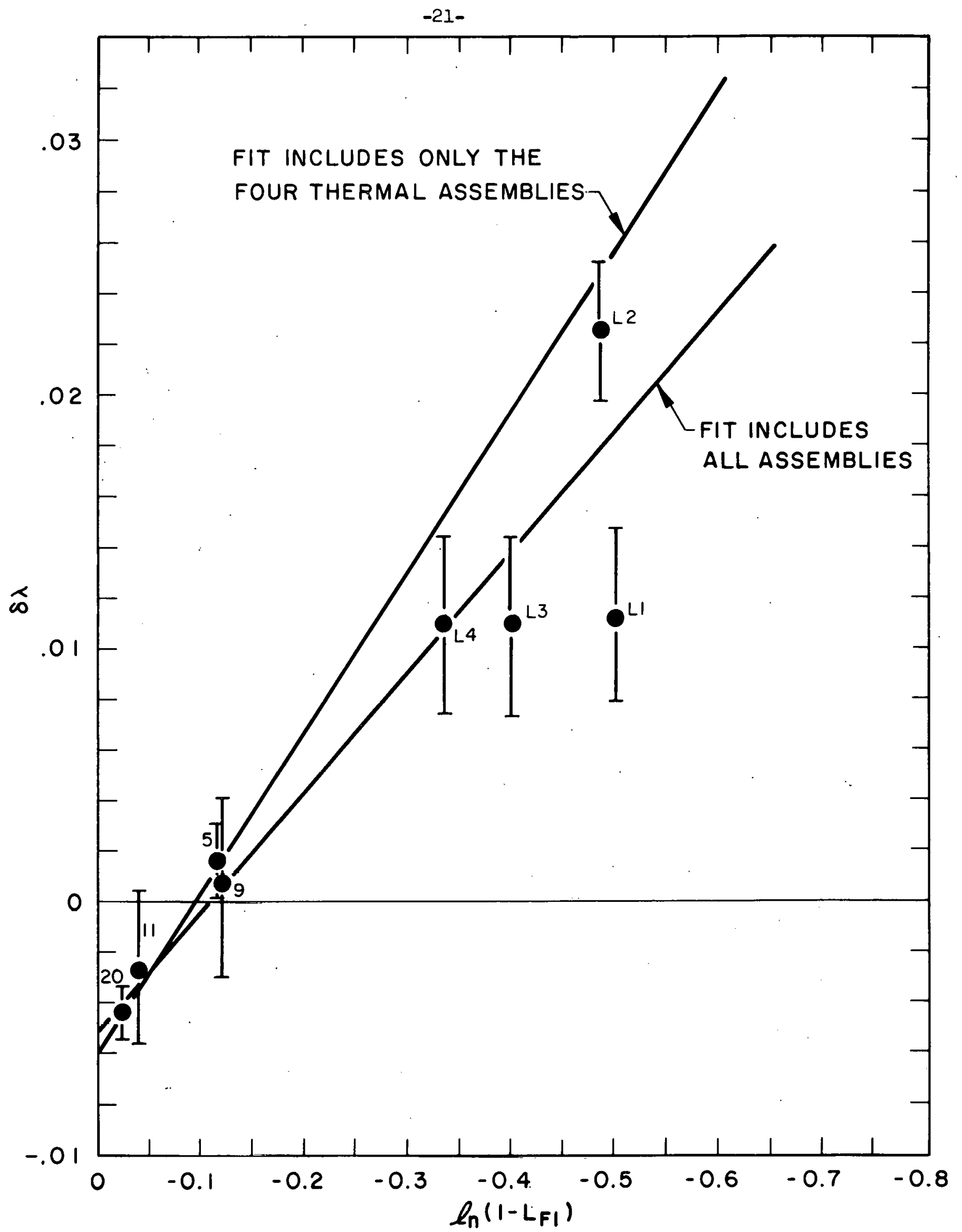

$\delta \lambda$ vs $2_{n}\left(1-I_{F 1}\right)$ for the U233

Assemblies Using ENDF/B-IV

FIGURE 2 


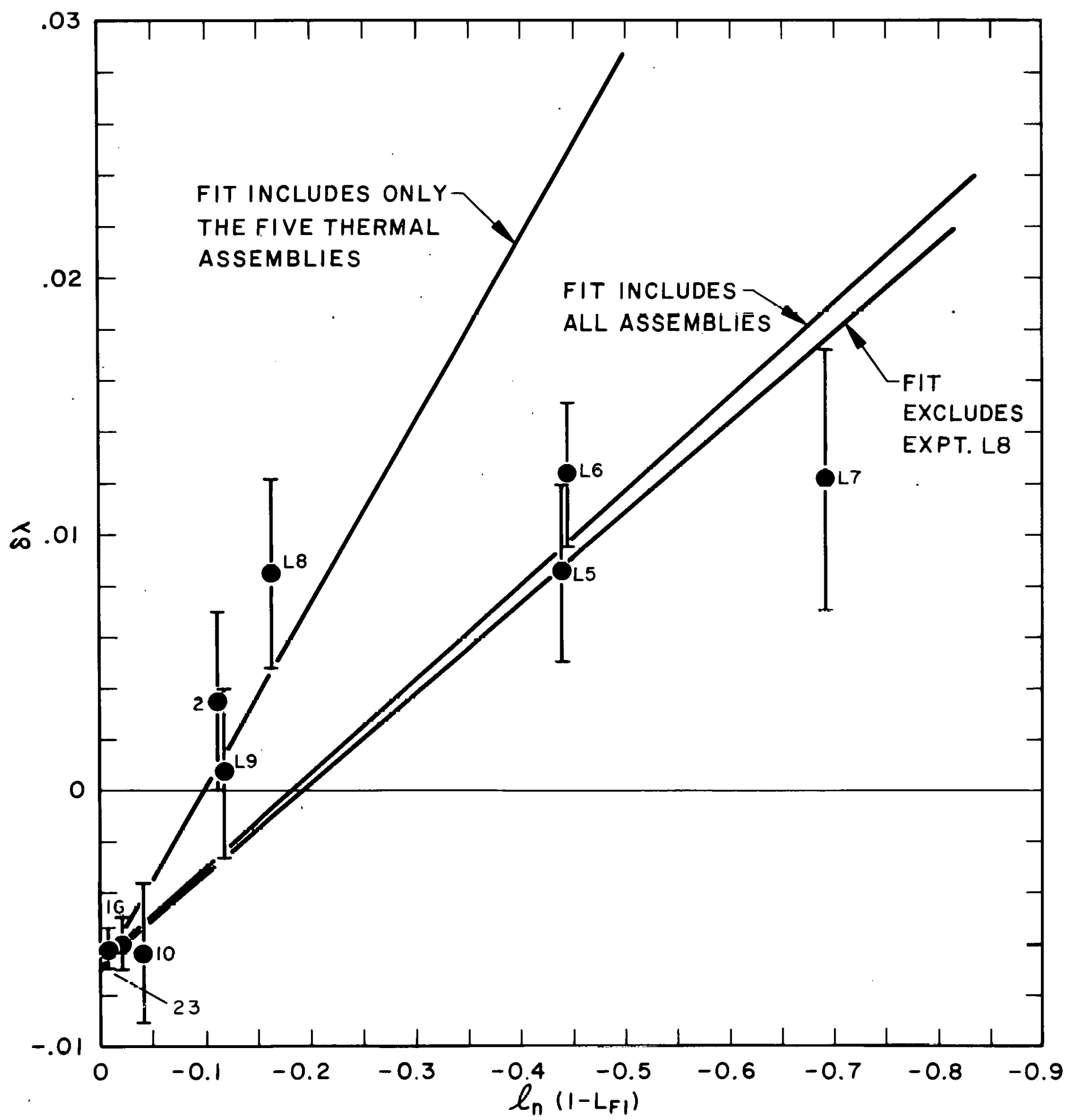

$\delta \lambda$ vs $\dot{x}_{n}\left(I-L_{F l}\right)$ for the UR35

Assemblies Using ENDF/B-IV

FIGURE 3 


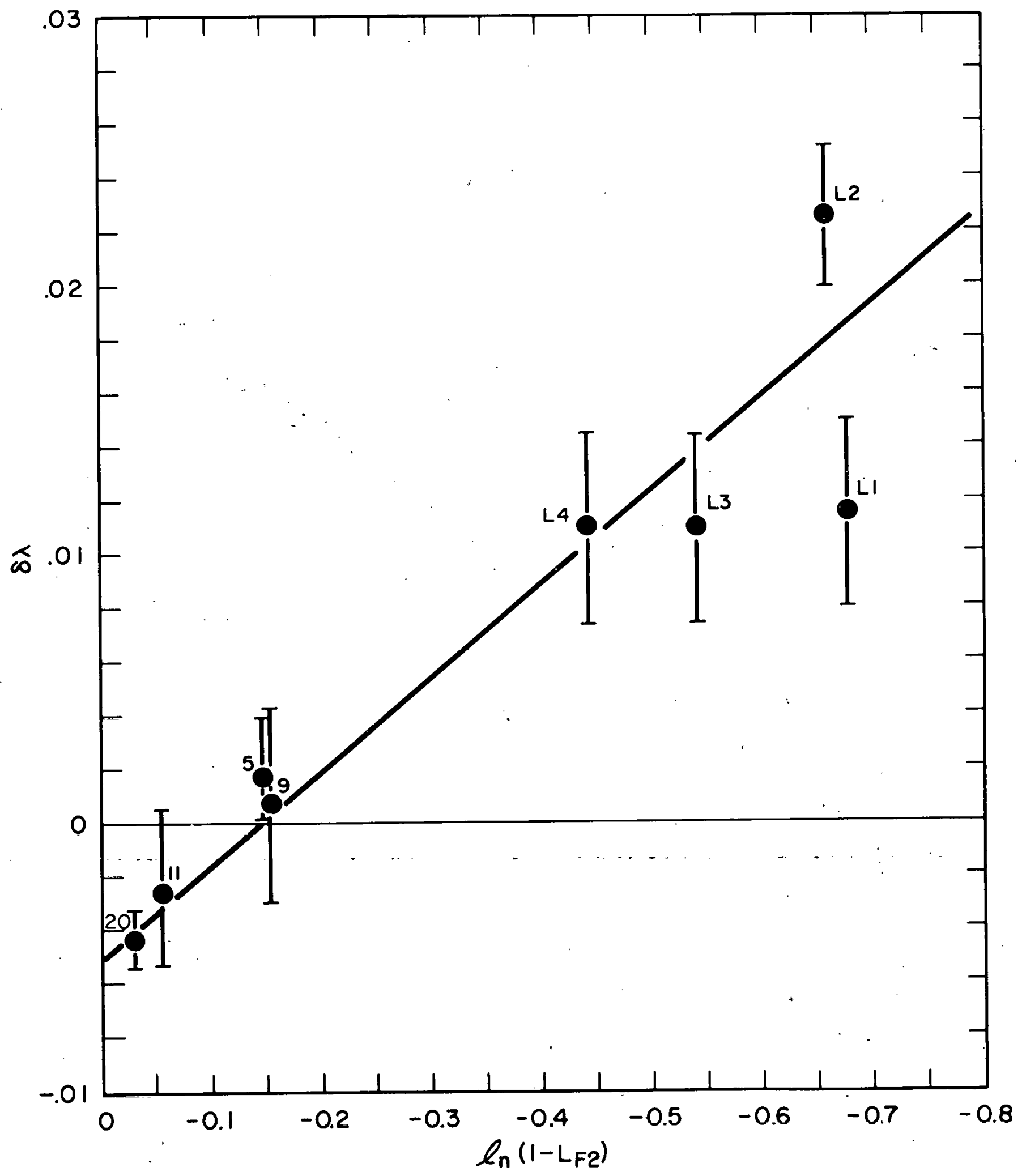

$\delta \lambda$ vs ${ }_{n}\left(1-L_{F 2}\right)$ for the U233

Assemblies Using ENDF/B-IV

FIGURE 4 


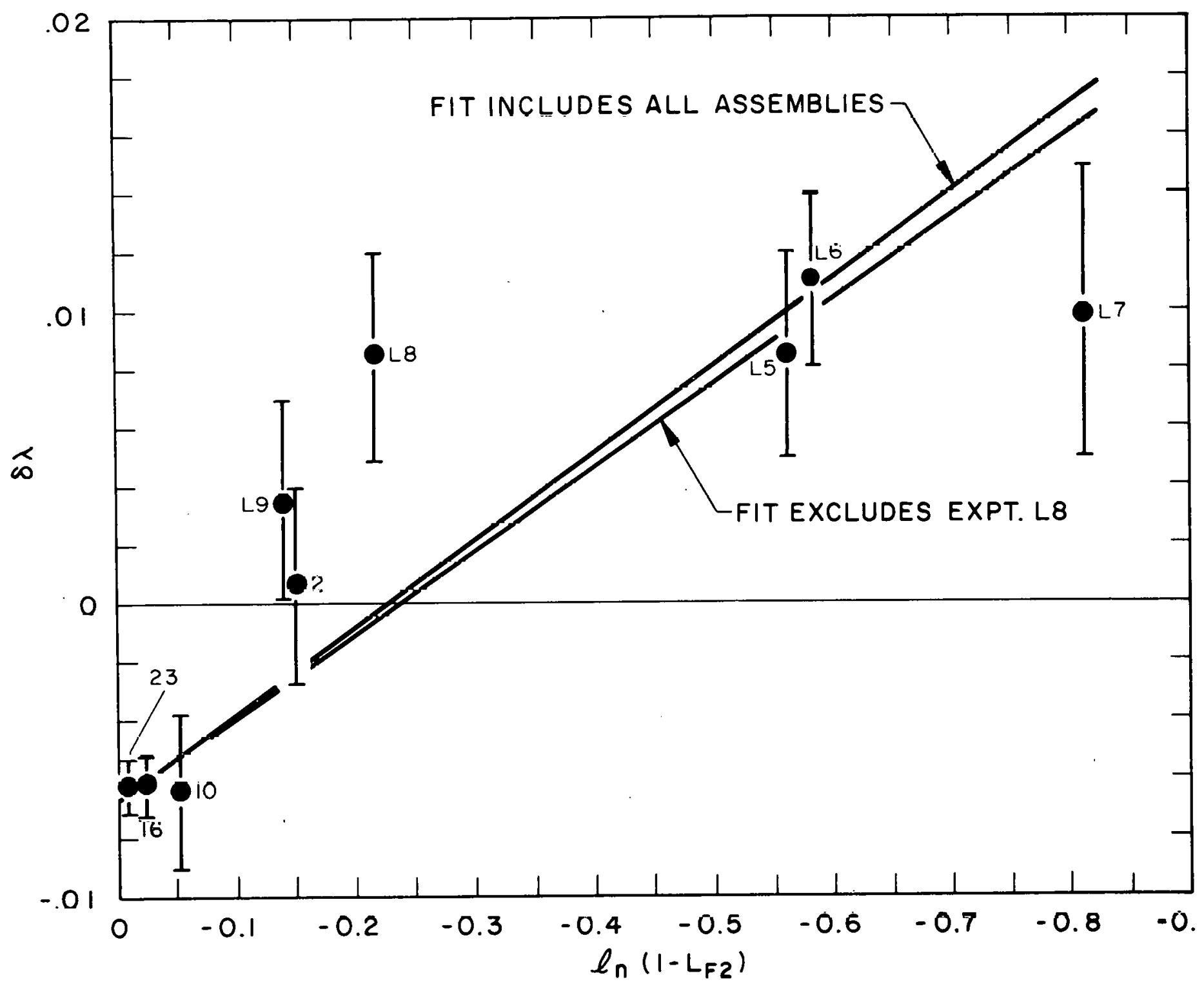

$\delta \dot{\lambda}$ vs $\sim_{n}\left(I-L_{F 2}\right)$ for the U235

Assemblies Using ENDF/B-IV 
A reference eigenvalue was computed for each assembly with PTMG and ENDF/B-IV data. Then for each change in data a $\delta \lambda$ was determined relative to this reference value. The sensitivities of $\lambda$ to the various parameters are summarized in Tables 7 and 8 . The following points are noteworthy:

1) Sensitivities to the EMDF/B version of oxygen are significant for the high-leakage assemblies and negligible for the thermal assemblies. The successive versions of oxygen (ENDF/B-I to ENDF/B-IV) show an increase in backscattering. For each oxygen change the $\delta \lambda$ versus epithermal ( $>0.625 \mathrm{eV}$ ) neutron leakage fraction is plotted for the U233 assemblies (F1g. 6) and the U235 assemblies (F1g. 7). The approximate linear varlation for each case can be used to estimate $\delta \lambda$ for the same changes in the oxygen cross sections for other assemblies having intermediate epithermal neutron leakage fractions (Table 5).

2) The fission neutron spectrum significantly affects fast neutron leakage. An estimate of the spectrum hardening increase necessary to eliminate the elgenvalue error was made as follows. Using a Maxwellian fission spectrum at. two mean energies ( $\overline{\mathrm{E}}=2.0 \mathrm{MeV}$ and $2.1 \mathrm{MeV}$ ) one finds that for the high leakage assemblies (Tables $7 \mathrm{~A}$ and $7 \mathrm{~B}$ ).

$$
\begin{aligned}
& \left(\frac{\delta \lambda}{\delta \bar{E}}\right)_{U 233} \simeq-\frac{0.0170}{0.10}=-0.170 \mathrm{MeV}^{-1} \\
& \left(\frac{\delta \lambda}{\delta \overline{\bar{E}}}\right)_{U 235} \simeq-\frac{0.014}{0.10}=-0.140 \mathrm{MeV}^{-1} .
\end{aligned}
$$


Sensitivitses of U233 Critical Assemblies to Changes in Nuclear Data

\begin{tabular}{|c|c|c|c|c|c|}
\hline \multirow[b]{2}{*}{ Data Component } & \multirow[b]{2}{*}{ Whange in Data Componen:- } & \multicolumn{4}{|c|}{ Change in E-genvalue $(\delta \lambda)$} \\
\hline & & $\mathrm{H} / \mathrm{U} 233=154(\mathrm{~L} 2)^{\mathrm{B}}$ & $381(\mathrm{~L} 3)$ & $1533(5)$ & $1986(11)$ \\
\hline \multirow{2}{*}{$\frac{\text { Oxygen Cross }}{\text { Sections }}$} & ENDF/B-IV $\rightarrow$ EADDF/B-III & -0.0041 & -0.0031 & -0.0008 & -0.0001 \\
\hline & ENDF/B-IV $\rightarrow$ BIDF/B-I & -0.0062 & -0.0044 & -0.0012 & -0.0002 \\
\hline \multirow[t]{3}{*}{ Fission Spectrum } & Maxwelliaz spectrum $\left\{\begin{array}{l}\bar{E}=2.0 \mathrm{MeV} \\
\mathrm{T}=1.333 \mathrm{MeV}\end{array}\right.$ & +0.0036 & +0.0029 & +0.0009 & +0.0003 \\
\hline & Maxwell lay spectrun $\left\{\begin{array}{l}\bar{E}=2.1 \mathrm{MeV} \\
\mathrm{T}=1.40 \mathrm{MeV}\end{array}\right.$ & -0.0134 & -0.0109 & -0.0049 & -0.0024 \\
\hline & Watt spectrun $(\bar{E}=2.0 \mathrm{MeV})$ & -0.0001 & +0.0001 & +0.0005 & +0.0004 \\
\hline Eyarogen Crosis & $\begin{array}{l}\text { Reduced thernal absorption } \\
\text { crcss section from } 0.332 b \text { to } \\
0.330 b\end{array}$ & +0.0004 & +0.0009 & +0.0026 & +0.0030 \\
\hline \multirow[t]{2}{*}{$\frac{\text { Uranium-233 }}{\text { Cross Sect1ons }}$} & $\begin{array}{l}\text { Recuced the inelastic cross } \\
\text { section by } 20 \% \text {. }\end{array}$ & -0.0004 & -0.0001 & 0.0000 & 0.0000 \\
\hline & $\begin{array}{l}\text { Inelastic crcss sections re- } \\
\text { duced by } 20 \% \text { and the elastic } \\
\text { crass sec-ion increased by an } \\
\text { equivalen amount to maintain } \\
\text { the same jotal cross section. }\end{array}$ & -0.0003 & -0.0001 & 0.0000 & 0.0000 \\
\hline
\end{tabular}




\section{TABLE 7B}

Sensitivities of U235 Critical Assemblies to Changes in Nuclear Data

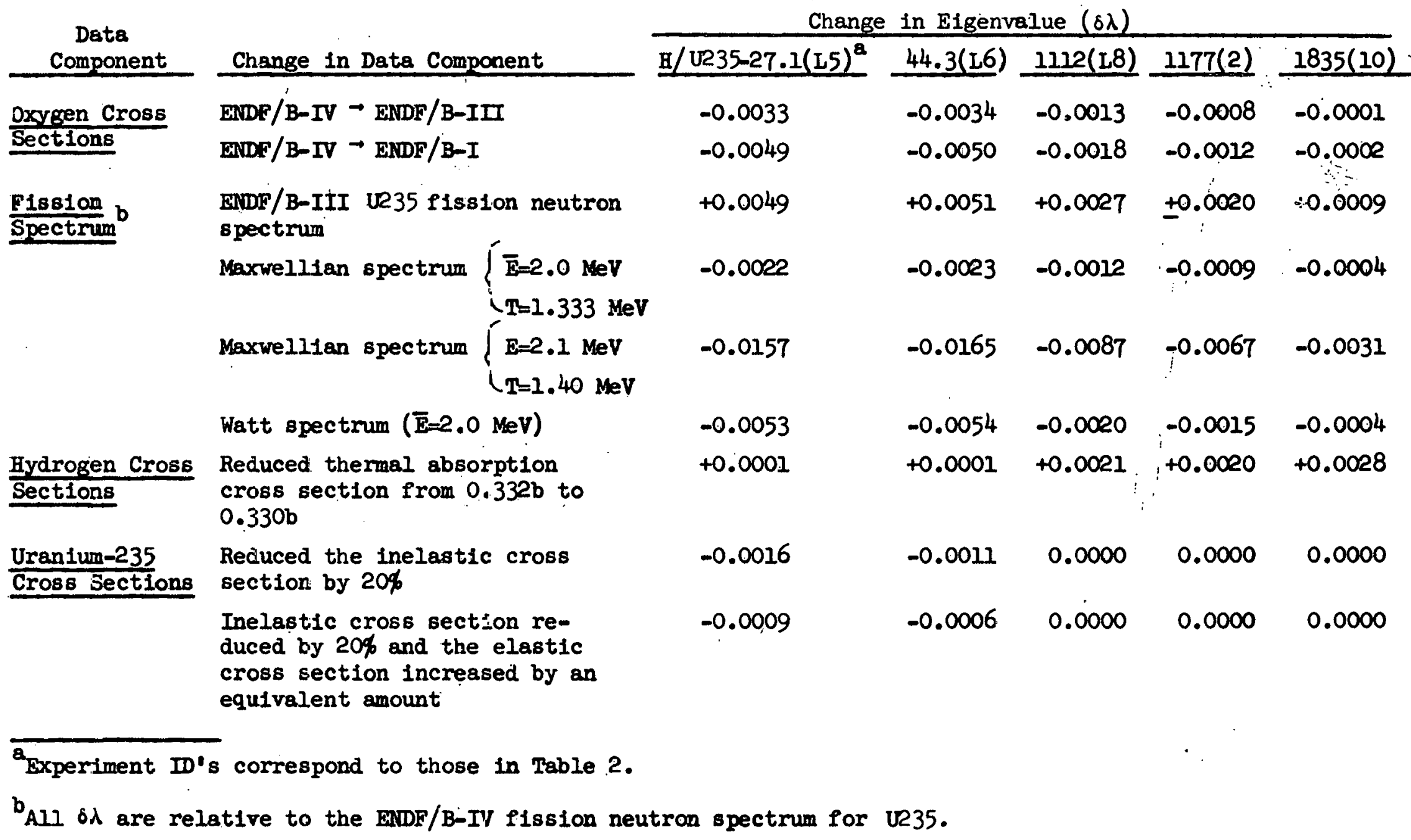




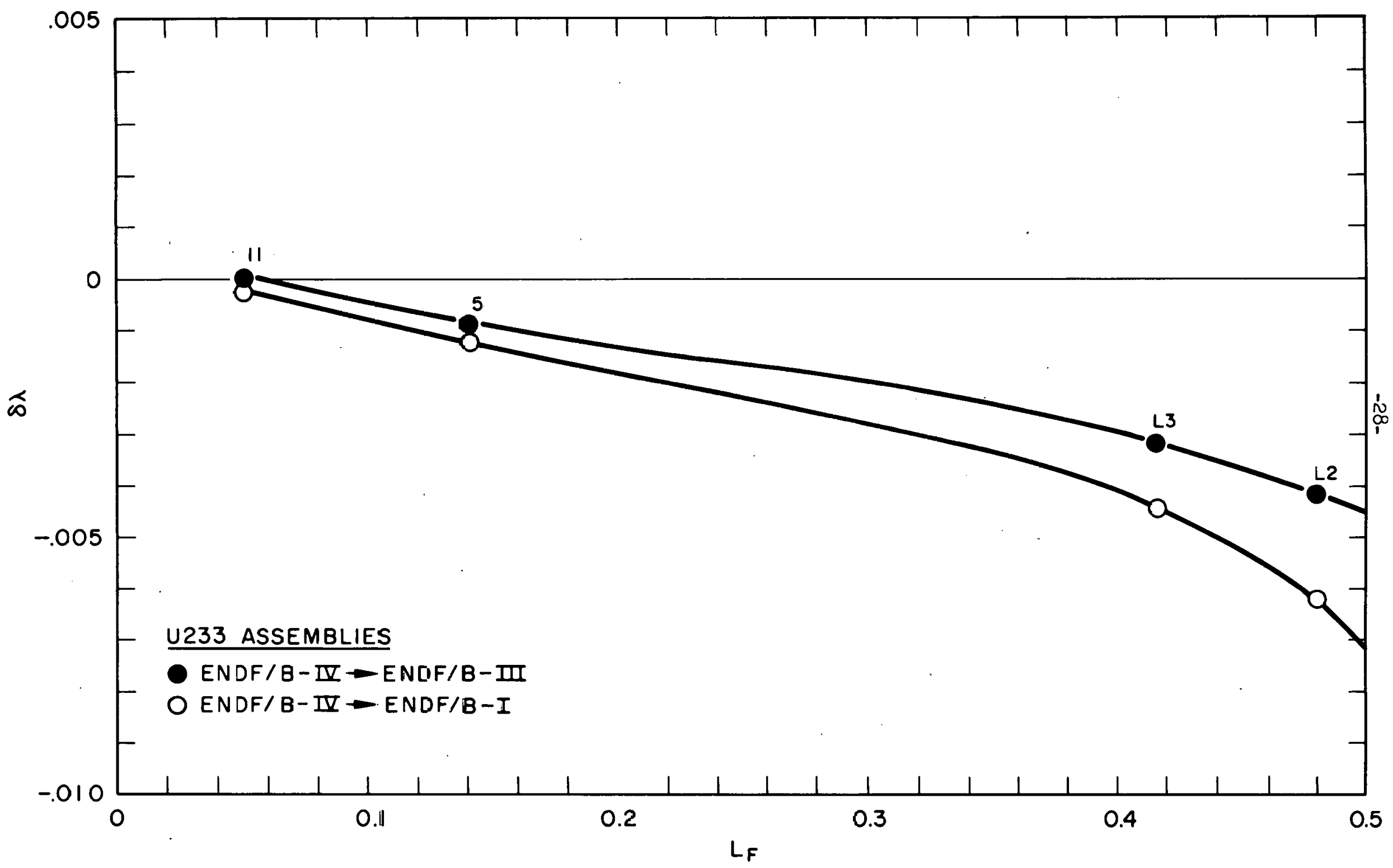

$\delta \lambda$ vs Epitinemal Neutron Leakage Fraction $L_{F}(>0.625 \mathrm{eV})$ for Various Oxygen Changes

FIGURE 6 


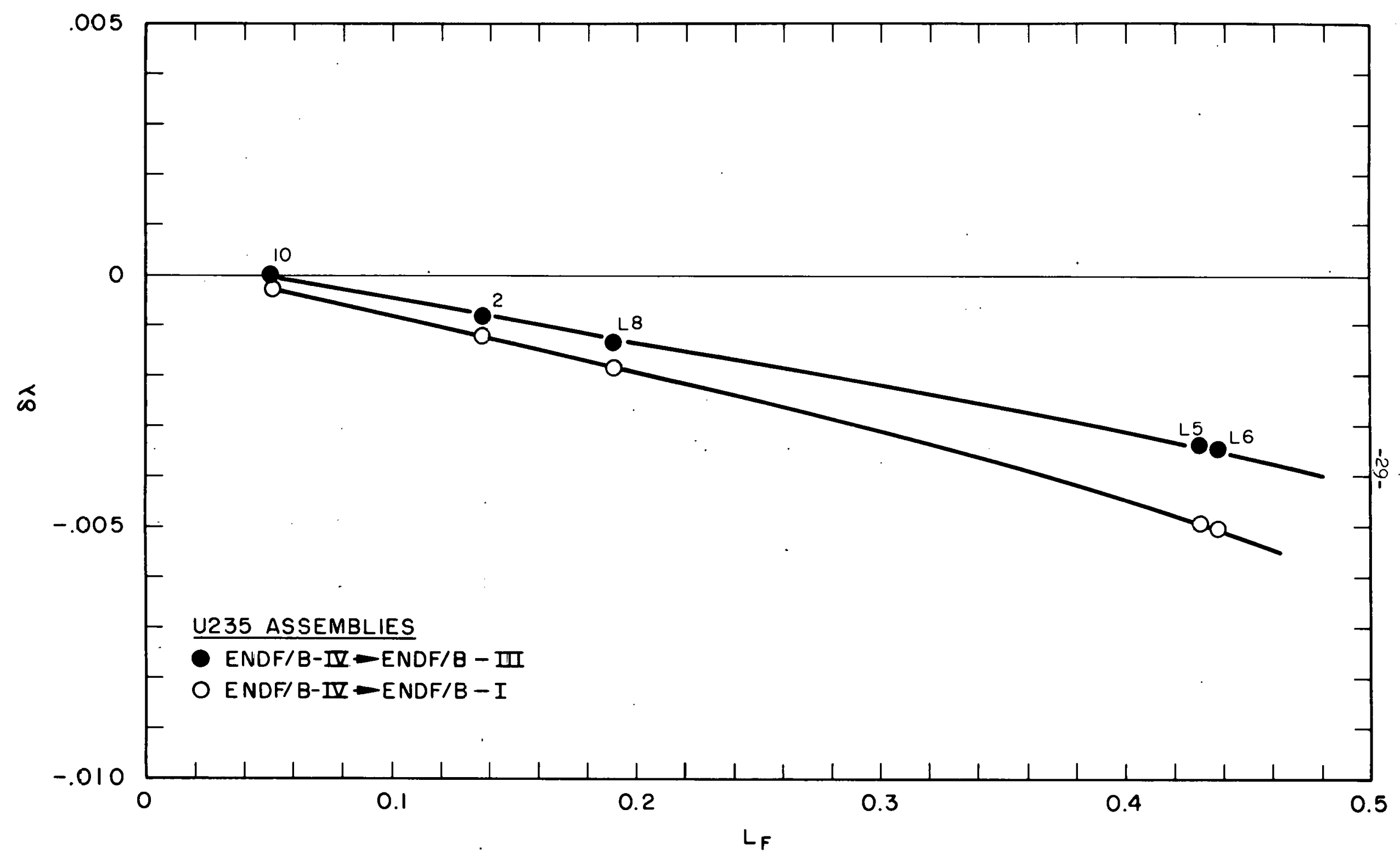

$\delta \lambda$ vs Epithermal Neutron Leakage Fraction $L_{F}(>0.625 \mathrm{eV})$ for
Various Oxygen Changes Various Oxygen
FIGURE 7 
Since the change of calculated eigenvalue from zero to $50 \%$ total leakage is +0.019 for $\mathrm{U} 233$ assemblies, Eq. (9) implies that the mean energy of the U233 fission neutron spectrum would have to be increased by $\sim 0.1 \mathrm{MeV}$, and a similar conclusion holds for the U235 assemblies. Such hardening of the fission spectra is inconsistent with the available data, and it is concluded that changes in the fission spectrum mean energy alone will not compensate for the increasing error in the calculated eigenvalues with fast neutron leakage fraction.

Sensitivity to the shape of the fission spectrum was also studied. The two most commonly used analytical representations of the experimental fission spectrum data are the Maxwellian,

$$
N(E)=\frac{2}{\sqrt{\pi} T} \sqrt{\frac{E}{T}} e^{-E / T}
$$

and the watt spectrum,

$$
N(E)=C e^{-A E} \sinh (B E)^{\frac{1}{2}}
$$

In Eqn. (11) the temperature $T$ is varied to $f$ it the experimental data, and in Eqn. (12) $C$ is a normalization constant, and $A$ and $B$ are varled to $\mathrm{flt}$ the data. The effect of the slight difference in shape between the Watt spectrum and the Maxwellian was determined for a mean fission neutron energy of $2.0 \mathrm{MeV}$. For the high leakage $U 233$ assembly $(H / U=154)$ use of the Watt spectrum reduced the calculated reactivity by 0.0037 relative to that computed with the Maxwellian spectrum. For the thermal assemblies the difference 
was negligible. A similar result was obtained for the high leakage U235 assemblies (the Watt spectrum lowered $\lambda$ by 0.0031 relative to a Maxwellian for the high leakage assemblies). These and other results are plotted in Figures 8 and 9.

Reasonable increases $(\sim 0.02 \mathrm{MeV})$ in the mean energies of the fission spectra can result in eigenvalue reductions of $\sim 0.3 \%$ in the high leakage assemblies, with negligible effect at low leakage. In addition, for a $2.0 \mathrm{MeV}$ mean energy the shape of the Watt spectrum leads to $0.3 \%$ lower elgenvalues than a Maxwellian for the highleakage criticals. Consequently, realistic variations in the energy distribution of the fission spectra are approximately equal to the mean energy in importance to calculated eigenvalues of high-leakage assemblies. For U235 ( $\bar{E}=1.985 \mathrm{MeV})$ such spectrum changes are not inconsistent with recent measurements (Ref. 17) which favor a harder spectrum of the Watt shape, especially at high energies. Increasing the mean energy of the ENDF/B-IV U233 fission spectrum $(\bar{E}=2.012 \mathrm{MeV})$ by $0.02 \mathrm{MeV}$ seems less credible (Ref. 18$)$.

3) Sensitivity to the hydrogen thermal absorption cross section was studled. Specifically, the $2200 \mathrm{~m} / \mathrm{sec}$ cross section $\left(\sigma_{\mathrm{aH}}\right)$ was reduced from $0.332 \mathrm{~b}$ to $0.330 \mathrm{~b}$. Th1s change increases the reactivity of the thermal assemblies by $0.3 \%$ and leaves the high leakage assemblies relatively unchanged. Other studies (Ref. 4) have suggested that $\sigma_{\mathrm{aH}}$ might be reduced to $0.330 \mathrm{~b}$, and such a change would reduce the value of $\frac{\partial \lambda}{\partial I_{F}}\left(I_{F}=\right.$ epithermal neutron leakage fraction) which results from calculations of homogeneous aqueous critical assemblies using ENDF/B-IV. 


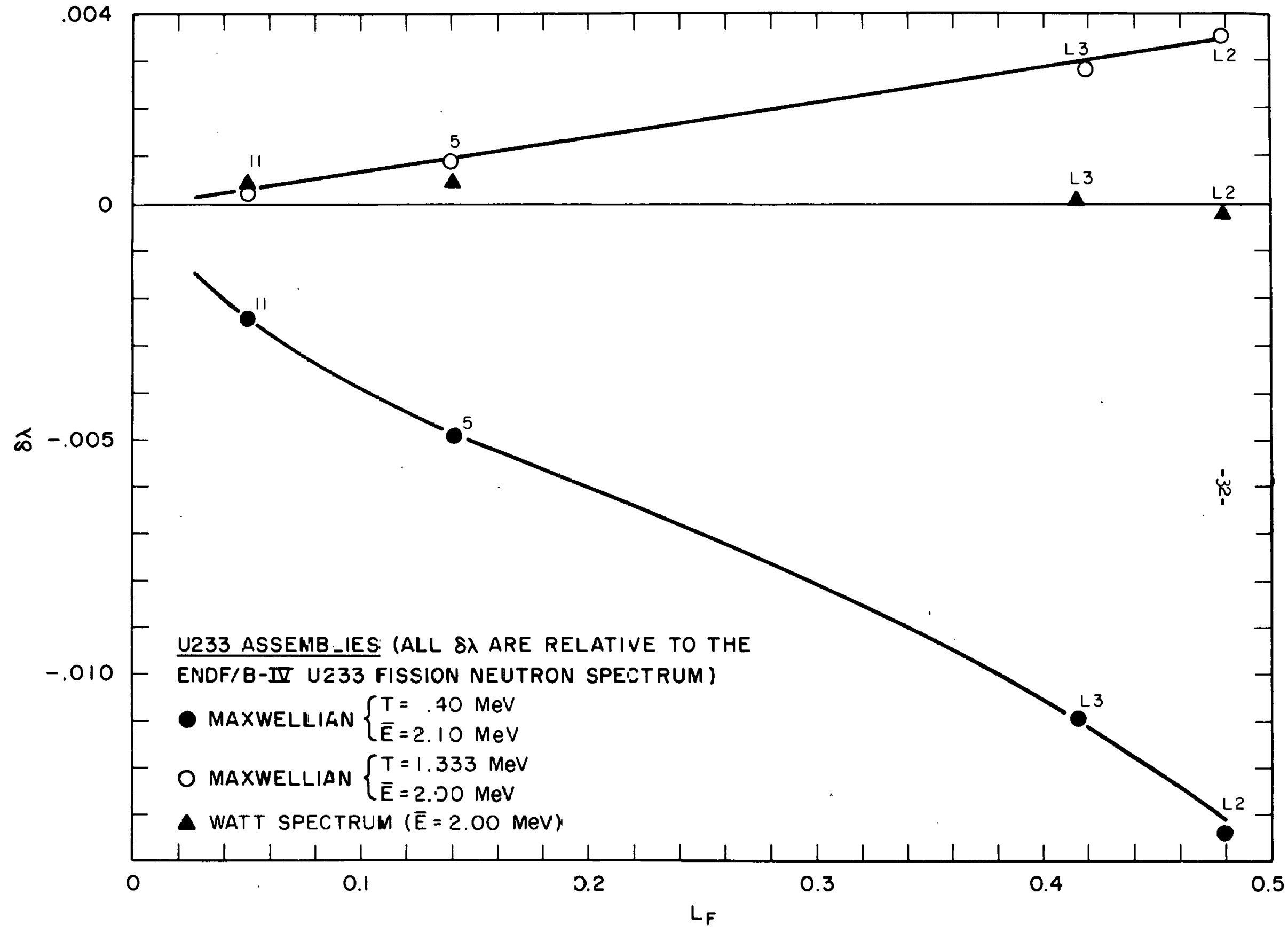

Sensitivities to Fission Speatra Vs Epithermal Leakage Fraction $\tau_{\mathrm{F}}(>0.625 \mathrm{eV})$

जाחm $?$ 


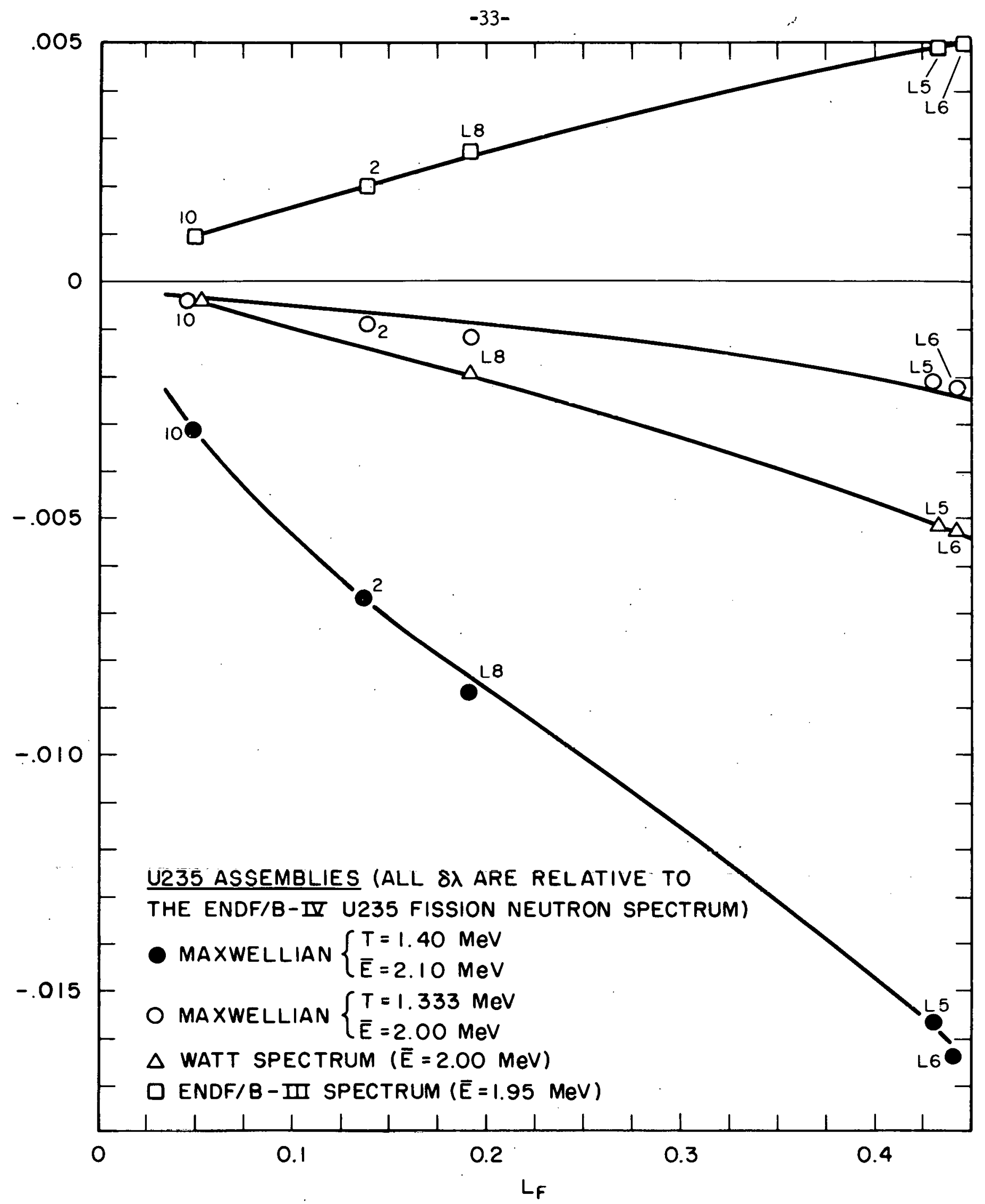

Sensitivities to Fission Spectra Vs Epithermal Leakage Fraction $\mathrm{L}_{\mathrm{F}}(>0.625 \mathrm{ev})$

FIGURE 9 
4) The uranium capture and fission resonance integrals were varied as shown in Table 8. In each case this was achieved by a uniform percentage change of the smooth multigroup cross sections. There are significant sensitivities for the U235 systems but not for U233. The relative importance of these sensitivities can be seen from the resonance integrals shown in Table 9. The ENDF/B-IV U235 fission integral is too large and the capture integral is low. This can account for at least $0.5 \%$ of the eigenvalue difference between small and large cores.

5) The inelastic cross sections for both fuel types were reduced by 20\%. The calculated $\delta \lambda^{\prime}$ s (Tables $7 \mathrm{~A}$ and $7 \mathrm{~B}$ ) were negligible. In fact, it is reasonable that the reduction of the inelastic scattering should be added to the elastic cross section so as to keep the total cross section unchanged. This was done, and the resulting $\delta \lambda$ 's were again negligible. It is concluded that reasonable perturbations of the inelastic cross sections of both fuels do not affect the trend in the calculated eigenvalues seen in this work. 
TABLE 8

Sensitivities of Elgenvalues to Uranium Capture and Fission Resonance Integrals

\begin{tabular}{|c|c|c|c|c|c|c|c|}
\hline \multirow[b]{2}{*}{ U233 } & \multirow[b]{2}{*}{$\operatorname{Exp} .:$} & \multicolumn{5}{|c|}{ Change in Eigenvalue } & \multirow[b]{2}{*}{20} \\
\hline & & $\mathrm{LI}$ & $\mathrm{L} 2$ & $\mathrm{~L} 3$ & $\mathrm{~L} 4$ & 5 & \\
\hline $\begin{array}{l}\text { Smooth capture integral } \\
\text { increased } 6.0 \text { b }\end{array}$ & & -.0021 & -.0017 & -.0007 & -.0005 & -.0002 & -.0001 \\
\hline $\begin{array}{l}\text { Smooth fission integral } \\
\text { increased } 13.0 \mathrm{~b}\end{array}$ & & +.0020 & $+.0016+$ & +.0009 & +.0008 & +.0005 & +.0005 \\
\hline U235 & Exp.: & $\mathrm{L} 5$ & L6 & & & $\mathrm{L} 8$ & 21 \\
\hline $\begin{array}{l}\text { Smooth capture integral } \\
\text { increased } 6.0 \mathrm{~b}\end{array}$ & & -.0077 & -.0053 & & 028 & -.0003 & .0002 \\
\hline $\begin{array}{l}\text { Smooth fission integral } \\
\text { increased } 10.0 \mathrm{~b}\end{array}$ & & +.0080 & +.0053 & & 027 & +.0005 & +.0004 \\
\hline
\end{tabular}


$-36-$

TABLE 9

Uranium Resonance Capture and Fission Integrals

Resonance Integral Above

$0.625 \mathrm{eV}$ (barns)

Fission

Capture

U235

ENDF/B-IV (Mat. 1261)

268

136

U235

BNL-325 ( $3^{\text {rd }}$ ed.) (Ref. 19

$259 \pm 5$

$142 \pm 6$

U233

ENDF/B-IV (Mat. 1260)

733

132

U233

$\mathrm{BNL}-325$ ( $3^{\text {rd }}$ ed.)

$735 \pm 13$

$138 \pm 6$ 
IV. THERMAL PARAMETER CONSTRAINTS DERIVED FROM THE GWIN-MAGNUSON CRITICALS

In this section the thermal criticality parameter constraint implied by the Gwin-Magnuson critical experiments is evaluated. Some details of the calculations are given in Part A, followed by calculated eigenvalues and reaction rates (Part B). Finally (Part C) the form of the constraint is derived and values are obtained for U233 and U235.

\section{A. PTMG Calculations}

The 23 Gwin-Magnuson U233 and U235 critical spheres and cylinders were analyzed with PTMG and ENDF/B-IV data. As a check, five experiments were also analyzed with RCPOl. These systems comprise spheres of 27.24-in. and 48.04-in. diameter, cylinders of 60.92-in. diameter and three U235 tubs of 107.7-in. diameter. Three of the U235 spheres and four U233 spheres contained boron poison. Leakage ranged from $1 \%$ to $17 \%$.

The present analysis is similar to previous studies by Staub et al. (Ref. 11) and by Steen (Ref. 18). The PTMG program performed a onedimensional multigroup $P_{\ell}$ calculation. In both axial and radial traverses a mesh of $\sim 0.1 \mathrm{~cm}$ was used for the outer $1-2 \mathrm{~cm}, 0.25 \mathrm{~cm}$ for $4 \mathrm{~cm}$, and 1 $\mathrm{cm}$ for the remainder. In the largest criticals, a $2 \mathrm{~cm}$ mesh was used in the central portion. Halving the mesh in selected problems produced completely insignificant changes of $\lambda$. Use of a $P_{1}$ flux angular approximation hardly affected results: for example, leakage changed by +0.0005 (out of 0.03034 ) and $\lambda$ changed by -0.0005 for experiment 21 . Th1s does not seem surprising in view of the small leakage in these cores and resultant near isotropy of the flux. 
The cylinders were analyzed in two steps:

(1) A radial traverse, Including the thin container wall. (In this calculation, axial leakage was represented with a single transverse buckling $B_{z}^{2}$ obtained from the measured critical solution height and an extrapolation distance of $2.5 \mathrm{~cm}$ ). Radial leakage was edited at the solution boundary in four fewgroups: $21 \mathrm{MeV}-821 \mathrm{keV}-5530 \mathrm{eV}-0.625 \mathrm{eV}-0 \mathrm{eV}$. In each few-group, a buckling was obtained which, when used in an infinite medium calculation, would reproduce the observed leakage. That 1s

$$
\left(\frac{\int J \cdot d S}{\int \Sigma_{A} \varphi \mathrm{dV}}\right)_{\substack{\text { Radial } \\ \text { Traverse }}} \stackrel{\text { set }}{=}\left(\frac{\mathrm{DB}_{r}^{2} \varphi}{\Sigma_{\mathrm{A}} \varphi}\right)_{\substack{\infty \\ \text { Medium }}}
$$

Assuming that the few-group $\Sigma_{A}$ and $D$ remain the same (a good approximation because leakage is small)

$$
B_{r}^{2}=\frac{\int J \cdot d S}{D \int \varphi d V}=\frac{2 \pi R J}{D \Phi}
$$

(2) An axial traverse with few-group transverse $B_{r}^{2}$ values obtained from the radial calculation. It was verified that the resulting four-group radial leakages agreed adequately with those calculated explicitly in (I).

This procedure for a typical cylinder (Experiment 16) gave results shown in Table 10 (Although an exact match of leakage could easily be obtained by adjusting the $\mathrm{B}_{\mathrm{r}}^{2}$ values, this was judged to be not worth doing.) The large differences among these few-group bucklings (more than a factor of two) are noteworthy. 
Calculated Few Group Radial Leakages and Inferred Bucklings (Experiment 16)

\begin{tabular}{|c|c|c|c|c|}
\hline Group & $\mathrm{D} \Phi$ & $\operatorname{Radial} \mathrm{T}$ & $\begin{array}{l}\text { Inferred } \\
\mathrm{B}_{\mathrm{r}}^{2} \times 10^{3}\left(\mathrm{~cm}^{-2}\right)\end{array}$ & $\begin{array}{l}\text { Resulting } \mathrm{D} \mathrm{B}_{\mathrm{r}}^{2} \varphi \\
\text { (Axial Calculation) }\end{array}$ \\
\hline 1 & 14.1787 & 0.00938 & 0.662 & 0.00942 \\
\hline 2 & 6.9112 & 0.00590 & 0.853 & 0.00591 \\
\hline 3 & 3.8152 & 0.00414 & 1.086 & 0.00415 \\
\hline 4 & 3.8766 & 0.00624 & 1.610 & 0.00624 \\
\hline TOTAL & 28.7817 & 0.02566 & 0.892 & 0.02572 \\
\hline
\end{tabular}

NOTE: The inferred $B_{r}^{2}=\frac{2 \pi R J}{D \Phi}$. 
The single net $B_{r}^{2}$ derived by this method to match the calculated total radial leakage is $0.892 \times 10^{-3} \mathrm{~cm}^{-2}$. This differs slightly from the $\mathrm{B}^{2}$ of the simply-buckled flux shape which is established over the central portion of the core. Figure 10 shows $J_{0}(B r)$, with $B_{r}^{2}=0.892 \times 10^{-3} \mathrm{~cm}^{-2}$, in comparison with the individual few-group shapes.

Table 1 shows the single $B_{r}^{2}$ value inferred from the total radial leakage cal ciliated for each soie. Agreement with experiment is good for the 60.92-in. diameter cylinders, but the calculation is $2.4 \%$ high for the 107.7-in. diameter tubs.

The single $\mathrm{B}_{\mathrm{z}}^{2}$ necessary to reproduce the calculated total axial leakage was inferred in a similar manner. Values are shown in Table 12 along with the corresponding total bucklings. A comparison of calculated and measured. total bucklings is shown in Figure 1l. The calculation lies about halfway between the measured fast and thermal $B^{2}$ values except for experiments 21 and 23 which are significantly out of line. Table 13 shows bucklings inferred from the calculated leakages for the spheres.

Figure 12 shows calculated few-group axial flux shapes for Experiment 16, along with the simply-buckled shape which matches the total leakage $\left(B_{z}^{2}=\right.$ $0.2224 \times 10^{-3} \mathrm{~cm}^{-2}$ ). This buckling is about $0.6 \%$ smaller than that of the simply-buckled flux shape established over the central portion of the core. (Although relatively small, this affects the comparison between measured and calculated bucklings shown in Figure 11). In addition, individual fewgroup leakages obtained with this single $B_{z}^{2}$ differ substantially from those actually calculated, as shown in Table 14A (such behavior is mentioned in Ref. 2, p. 368). 


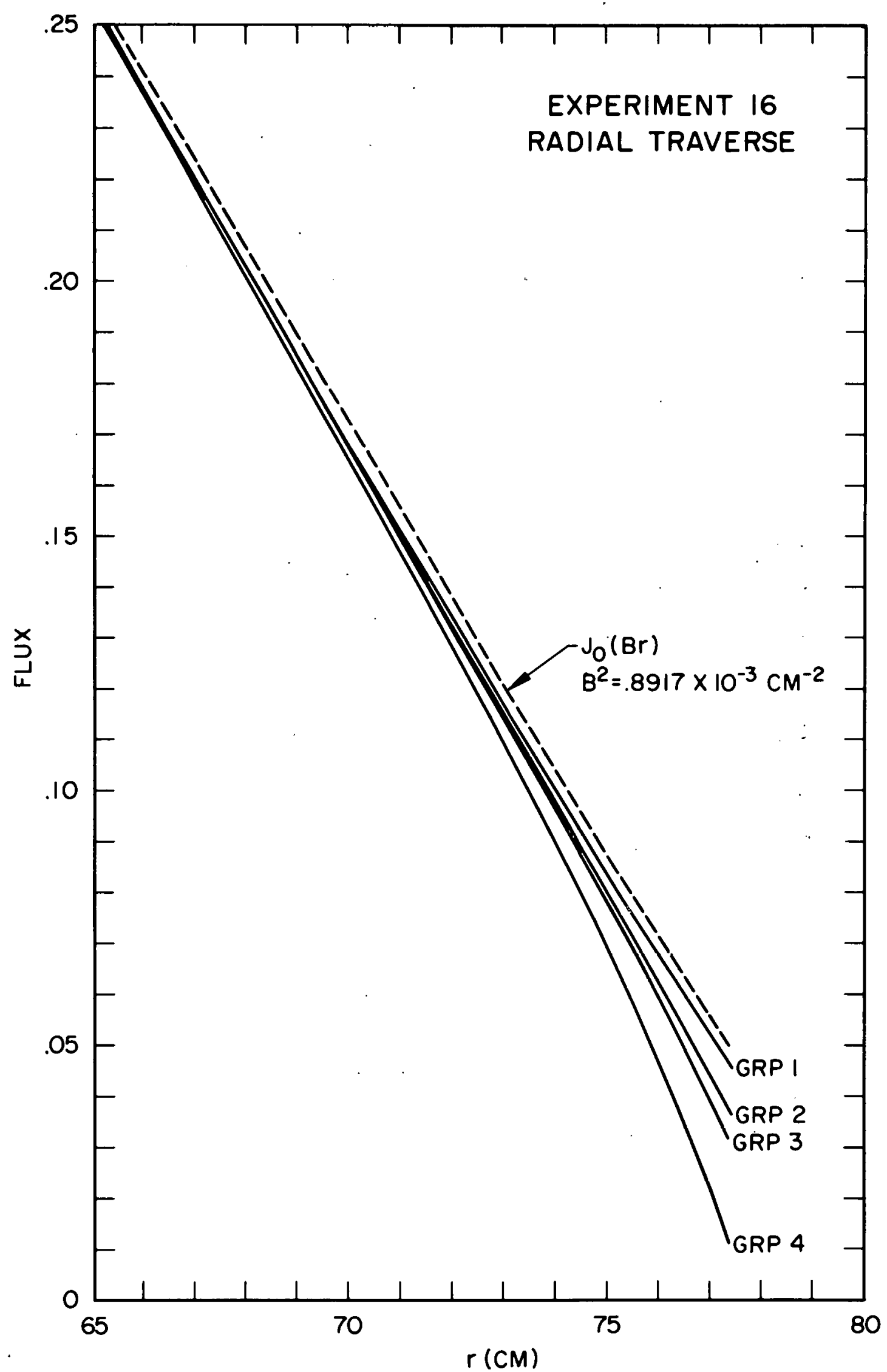

Few Group Radial Flux Shapes Near the Boundary (Exp. 16) FIGUKE' 10 
TABLE 11

Comparison of Calculated and Neasured

Radial Bucklings for Cylinders

Experiment

\begin{tabular}{|c|c|}
\hline U235 & 12 \\
\hline \multirow{4}{*}{$\begin{array}{l}(60.92-10 . \\
\text { diam.) }\end{array}$} & 13 \\
\hline & 14 \\
\hline & 15 \\
\hline & 16 \\
\hline U233 & 17 \\
\hline \multirow{4}{*}{$\begin{array}{l}(60.92-i n . \\
\text { diam.) }\end{array}$} & 18 \\
\hline & 19 \\
\hline & 20 \\
\hline & Average \\
\hline U235 & 21 \\
\hline \multirow{2}{*}{$\begin{array}{l}\left(107.7^{-1 n .}\right. \\
\text { diam. }\end{array}$} & 22 \\
\hline & 23 \\
\hline
\end{tabular}

$$
\mathrm{B}_{\mathrm{r}}^{2} \times 10^{3}\left(\mathrm{~cm}^{-2}\right)
$$

Calculated Measured (Ref. 2)

0.878

0.881

0.886

0.883

0.890

0.890

0.892

0.882

0.885

0.889

0.893

0.886

0.294

0.295

$\underline{0.296}$

0.295 
TABLE 12

Comparison of Calculated and Measured Total Bucklings for Cylinders and Tubs

\begin{tabular}{|c|c|c|c|c|c|}
\hline \multirow[b]{3}{*}{ Exp. } & \multicolumn{5}{|c|}{$B^{2}\left(\times 10^{3} \mathrm{~cm}^{-2}\right)$} \\
\hline & \multicolumn{3}{|c|}{ Calculated } & \multicolumn{2}{|c|}{ Messured $(\operatorname{Ref} .2)$} \\
\hline & Axial & Radial & Total & Thermal & Past \\
\hline 12 & 3.633 & 0.878 & 4.511 & $4.67 \pm .11$ & 4.46 \\
\hline 13 & 3.366 & 0.881 & 4.247 & $4.31 \pm .10$ & 4.17 \\
\hline 14 & 1.548 & 0.886 & 2.434 & $2.47 \pm .05$ & 2.42 \\
\hline 15 & 0.7806 & 0.890 & 1.671 & $1.67 \pm .03$ & 1.66 \\
\hline 16 & 0.2224 & 0.892 & 1.114 & $1.11 \pm .02$ & 1.10 \\
\hline 17 & 3.102 & 0.882 & 3.984 & $4.09 \pm .10$ & 3.93 \\
\hline 18 & 2.257 & 0.885 & 3.142 & $3.20 \pm .07$ & 3.11 \\
\hline 19 & 1.380 & 0.889 & 2.269 & $2.29 \pm .05$ & 2.25 \\
\hline 20 & 0.4653 & 0.893 & 1.358 & $1.35 \pm .03$ & 1.35 \\
\hline 21 & 1.062 & 0.294 & 1.356 & $1.31 \pm .02$ & \\
\hline 22 & 0.6333 & 0.295 & 0.928 & $0.93 \pm .01$ & \\
\hline 23 & 0.1624 & 0.296 & 0.458 & $0.44 \pm .01$ & \\
\hline
\end{tabular}




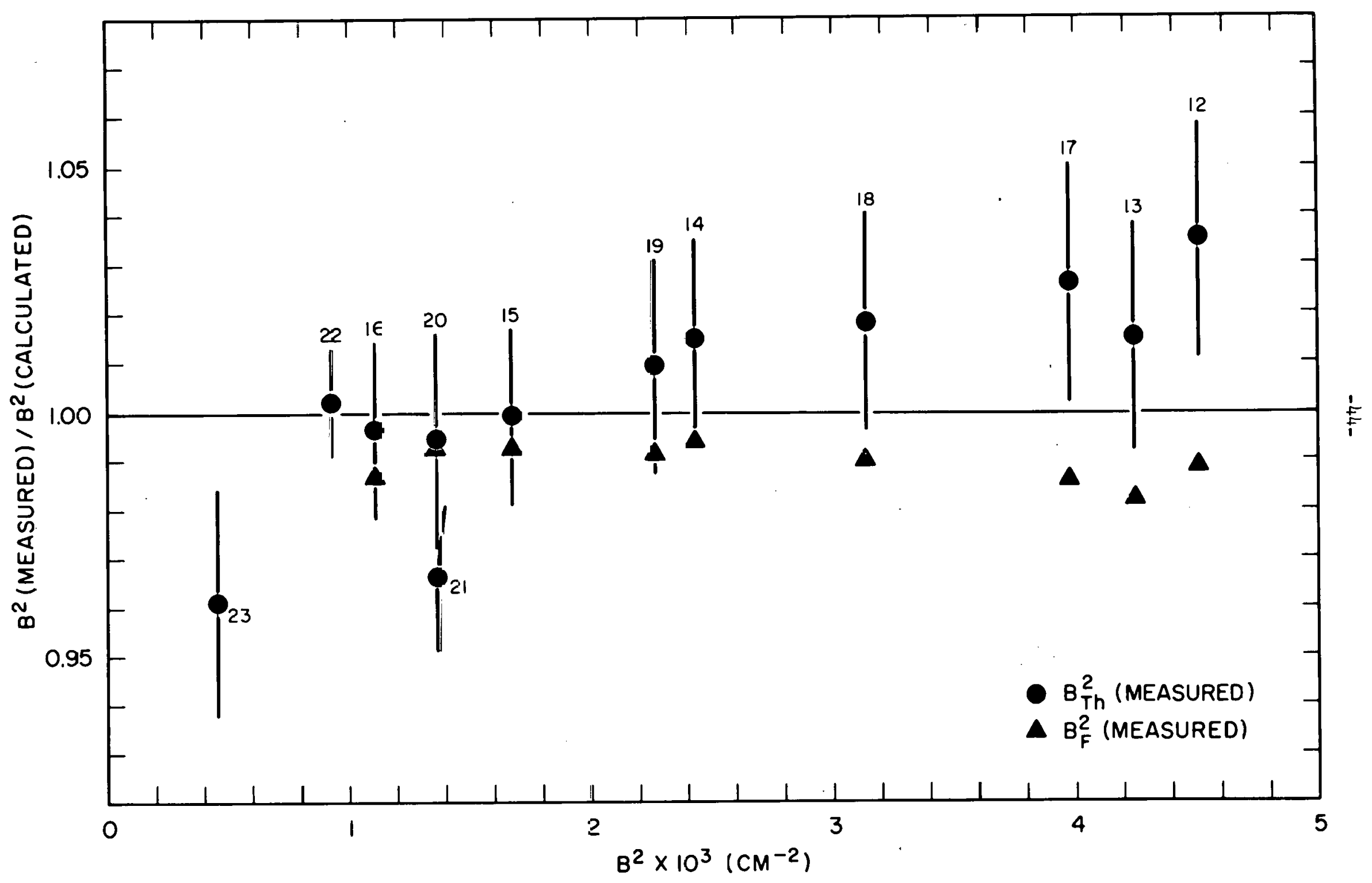

Ratio of Measured to Calculated Buckling for Gwin-Magnuson Cylinders 
$-45-$

TABTE I3

\section{Bucklings Inferred from Calculated Leakages for Spheres}

Experiment

1

2

3

4

5

6

7

8

9

10

11
$\mathrm{B}^{2} \times 10^{3}\left(\mathrm{~cm}^{-2}\right)$

6.860

6.842

6.828

6.823

6.872

6.867

6.862

6.857

6.853

2.402

2.406 
$-46-$

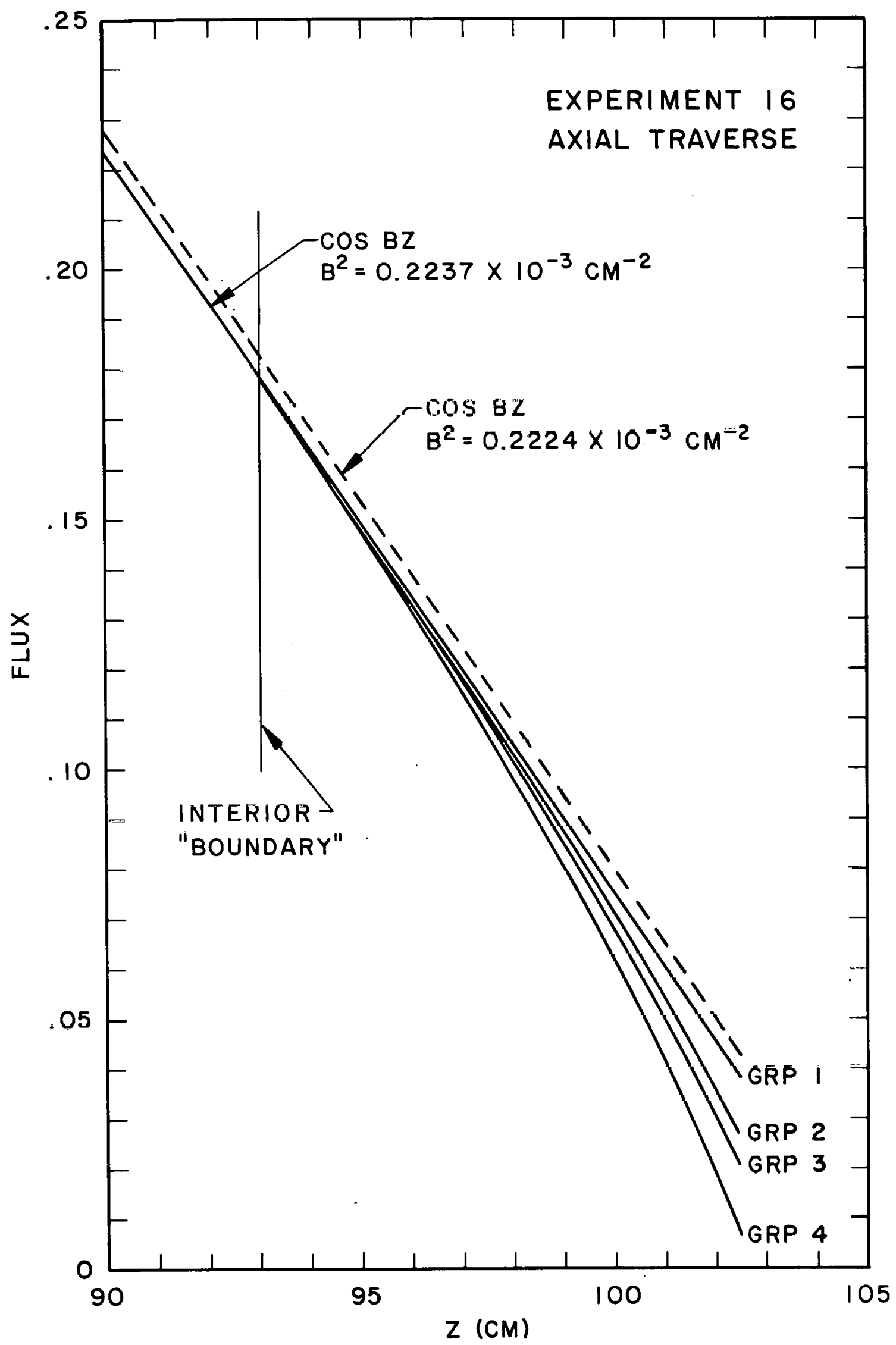

Few Group Axial Flux Shapes Near the Boundary (Experiment 16) 


\begin{tabular}{|c|c|c|c|c|}
\hline Group & $D Q$ & $\mathrm{~B}_{\mathrm{z}}^{2} \times 10^{3}\left(\mathrm{~cm}^{-2}\right)$ & $\mathrm{J}$ & $\mathrm{D} \Phi \times\left\langle\mathrm{B}_{\mathrm{z}}^{2}\right\rangle$ \\
\hline 1 & 14.2271 & 0.1631 & 0.00232 & 0.00316 \\
\hline 2 & 6.9317 & 0.2192 & 0.00152 & 0.00154 \\
\hline 3 & 3.8181 & 0.2907 & 0.00111 & 0.00085 \\
\hline 4 & 3.8764 & 0.3792 & 0.00147 & 0.00086 \\
\hline Total & 28.8533 & 0.2224 & 0.00642 & 0.00642 \\
\hline
\end{tabular}

* Note $\left\langle\mathrm{B}_{\mathrm{z}}^{2}\right\rangle=0.2224 \times 10^{-3} \mathrm{~cm}^{-2}$.

The inferred $B_{2}^{2}=\frac{J}{D \Phi}$. 
At a distance of $9.46 \mathrm{~cm}$ inside the core boundary, these differences are much reduced, as shown in Table $14 \mathrm{~B}$. Now, the individual $\mathrm{B}_{\mathrm{z}}^{2}$ values which match the few-group leakages are nearly the same, and the $\mathrm{B}_{\mathrm{z}}^{2}$ inferred from the total leakage is close to that of the single simply-buckled flux shape $\left(B_{z}^{2}=.2237\right.$ $\times 10^{-3} \mathrm{~cm}^{-2}$ ) established over the interior of the core (Figure 12).

\section{B. Calculated Results}

lables 15 and 16 show crfticulliy resulis and wajor reaction rates of interest. The experimental elgenvalues quoted for the spheres are the "corrected values" from Ref. 11 , which incorporate corrections for several small effects. For the cylinders, only the room return correction is applicable, and this has been obtained by the method of Ref. 11.

Figures 13 and 14 show $\lambda_{\text {calc }} e^{-\lambda}$ exp versus leakage along with the best-fit line obtained from the EMDF/B-IV analysis of small cores. The Gwin-Magnuson criticals show a leakage dependence of $\lambda_{\text {re. } \mathrm{re}}$ and this appears to be consistent with that inferred from analysis of the small cores.

As a check, the PTMG results are compared with RCP Monte Carlo calculations which were done for experiments $1,5,16,20$, and 23. Table 17 shows a comparison of the PTMG and RCP elgenvalues, and calculated total leakages are compared in Table 18. The PTMG eigenvalues are consistently higher than those from RCP by about 0.11\%. This is attributed to differences between the two calculational methods, mostly in leakage rates (Table 18), as well as possible slight lack of eigenfunction convergence of the RCP results for the very large Experiment \#23. The leakage results are consistent with a fixed leakage difference of about 0.0007 between RCP and PTMG. 


\begin{tabular}{|c|c|c|c|c|}
\hline & & Inferred & & \\
\hline Group & DE & $\mathrm{B}_{\mathrm{z}}^{2} \times 10^{3}\left(\mathrm{~cm}^{-2}\right)$ & $\mathrm{J}$ & $D \times\left\langle B_{z}^{2}\right\rangle$ \\
\hline 1 & 14.0126 & 0.2176 & 0.00305 & 0.00314 \\
\hline 2 & 6.8302 & 0.2254 & 0.00154 & 0.00153 \\
\hline 3 & 3.7621 & 0.2285 & 0.00086 & 0.00084 \\
\hline 4 & 3.8181 & 0.2383 & 0.00091 & 0.00085 \\
\hline & 28.4230 & 0.2237 & 0.00636 & 0.00636 \\
\hline & & & & + \\
\hline & & & & $\therefore$ \\
\hline Note & $=030$ & $0^{-3} \mathrm{~cm}^{-2}$ & & $\vdots$ \\
\hline
\end{tabular}


Calculated Reaction Rates for U235 Criticals

\begin{tabular}{|c|c|c|c|c|c|c|c|}
\hline Exp. & $\lambda_{\text {exp. }}$ & $\lambda_{\text {calc. }}$ & Ther. VFiss. & Ep1. VFiss. & Ther. A & Ther. $A_{x}$ & Leakage \\
\hline 1 & 1.00026 & c.99831 & 0.97708 & 0.02123 & 0.80 .460 & 0.47271 & 0.17285 \\
\hline $2 *$ & 0.99975 & C. 99800 & 0.97324 & 0.02477 & 0.80 .421 & 0.47090 & 0.16992 \\
\hline $3 *$ & 0.99994 & $C .99494$ & 0.96682 & 0.02811 & 0.80316 & 0.46786 & 0.16777 \\
\hline 4* & 0.99924 & 0.996 .37 & 0.96652 & 0.02985 & 0.80244 & 0.46773 & 0.16688 \\
\hline 10 & 1.00031 & 0.99567 & 0.97821 & 0.01746 & 0.51212 & 0.47320 & 0.06702 \\
\hline 12 & 0.99970 & $0.998 i 47$ & 0.97931 & 0.01915 & 0.85866 & 0.47375 & 0.11968 \\
\hline 13 & & 0.99761 & 0.97870 & $0.0 ; 891$ & 0.86580 & 0.47345 & 0.11262 \\
\hline 14 & & 0.99802 & 0.98043 & 0.01759 & 0.91117 & 0.47428 & 0.06788 \\
\hline 15 & & 0.99797 & 0.98089 & 0.01708 & 0.93178 & 0.47449 & 0.04748 \\
\hline 16 & & 0.99480 & $0.9781 \varepsilon$ & 0.01662 & 0.94732 & 0.47317 & 0.03214 \\
\hline 21 & & 0.99338 & 0.97664 & 0.01675 & 0.94049 & .0 .47243 & 0.03880 \\
\hline 22 & & 0.99383 & 0.97734 & 0.01649 & 0.95252 & 0.47277 & 0.02686 \\
\hline 23 & $\downarrow$ & 0.99574 & $0.9^{m} 948$ & 0.01626 & 0.95604 & 0.47380 & 0.01341 \\
\hline
\end{tabular}

\section{Boron loaded}

Ther $A_{x}$ is the thermal absorption rate in fissile uranium. 
TABLE 16

Calculated Reaction Rates for U233 Criticals

\begin{tabular}{|c|c|c|c|c|c|c|c|}
\hline Exp. & $\lambda_{\text {exp. }}$ & $\lambda_{\text {calc. }}$ & Ther. Wiss. & Ep1. VF18s. & Ther. A & Ther. $A_{x}$ & Leakage \\
\hline 5 & 0.99949 & 1.00319 & 0.94957 & 0.05362 & 0.78882 & 0.41443 & 0.17688 \\
\hline $6 *$ & 1.00009 & 1.00370 & 0.94786 & 0.05584 & 0.78846 & 0.41370 & 0.17592 \\
\hline$p^{*}$ & 1.00015 & 1.00350 & 0.94564 & 0.05786 & 0.78807 & 0.41274 & 0.17510 \\
\hline $8 *$ & 0.99930 & 1.00346 & 0.94360 & 0.05985 & 0.78764 & 0.41184 & 0.17434 \\
\hline g* & 0.99942 & 1.00286 & 0.94107 & 0.06179 & 0.78718 & 0.41075 & 0.17364 \\
\hline 11 & 0.99944 & 0.99814 & 0.95257 & 0.04556 & 0.90020 & 0.41576 & 0.06855 \\
\hline 17 & 0.99970 & 0.99899 & 0.95087 & 0.04811 & 0.85839 & 0.41493 & 0.10938 \\
\hline 18 & & 1.00023 & 0.95332 & 0.04691 & 0.88021 & 0.41600 & 0.08800 \\
\hline 19 & & 0.99909 & 0.95360 & 0.04549 & 0.90386 & 0.41612 & 0.06490 \\
\hline 20 & $\downarrow$ & 0.99669 & 0.95269 & 0.04400 & 0.92957 & 0.41572 & 0.03975 \\
\hline
\end{tabular}

\footnotetext{
* Bcron loaded.

Ther $\dot{A}_{x}$ is the thermal absorption rate in fissile uranium.
} 


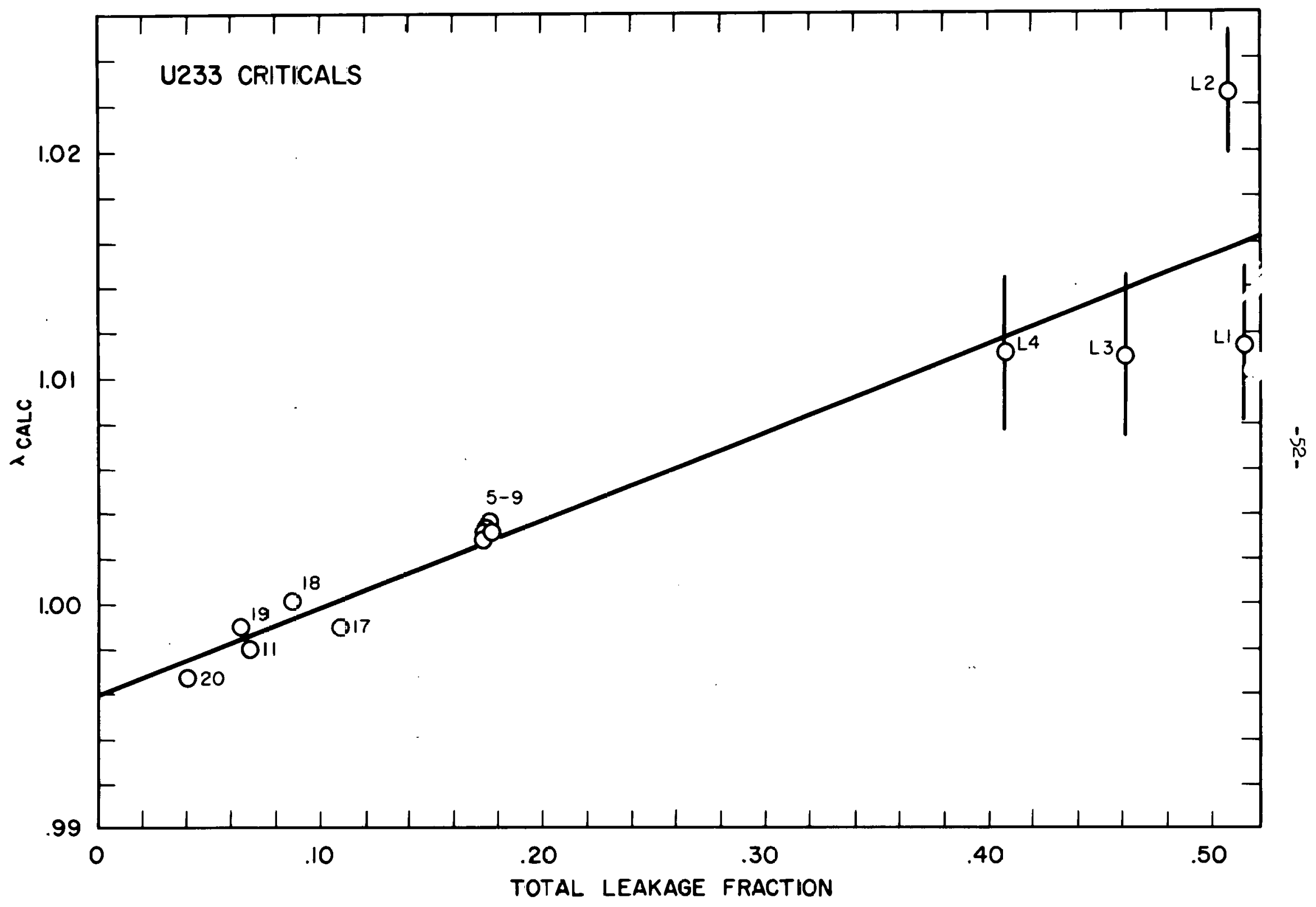

Calculated Eigenvalue Versus Total Leakage Fracticn for U233 Criticals

FIGURE 13 


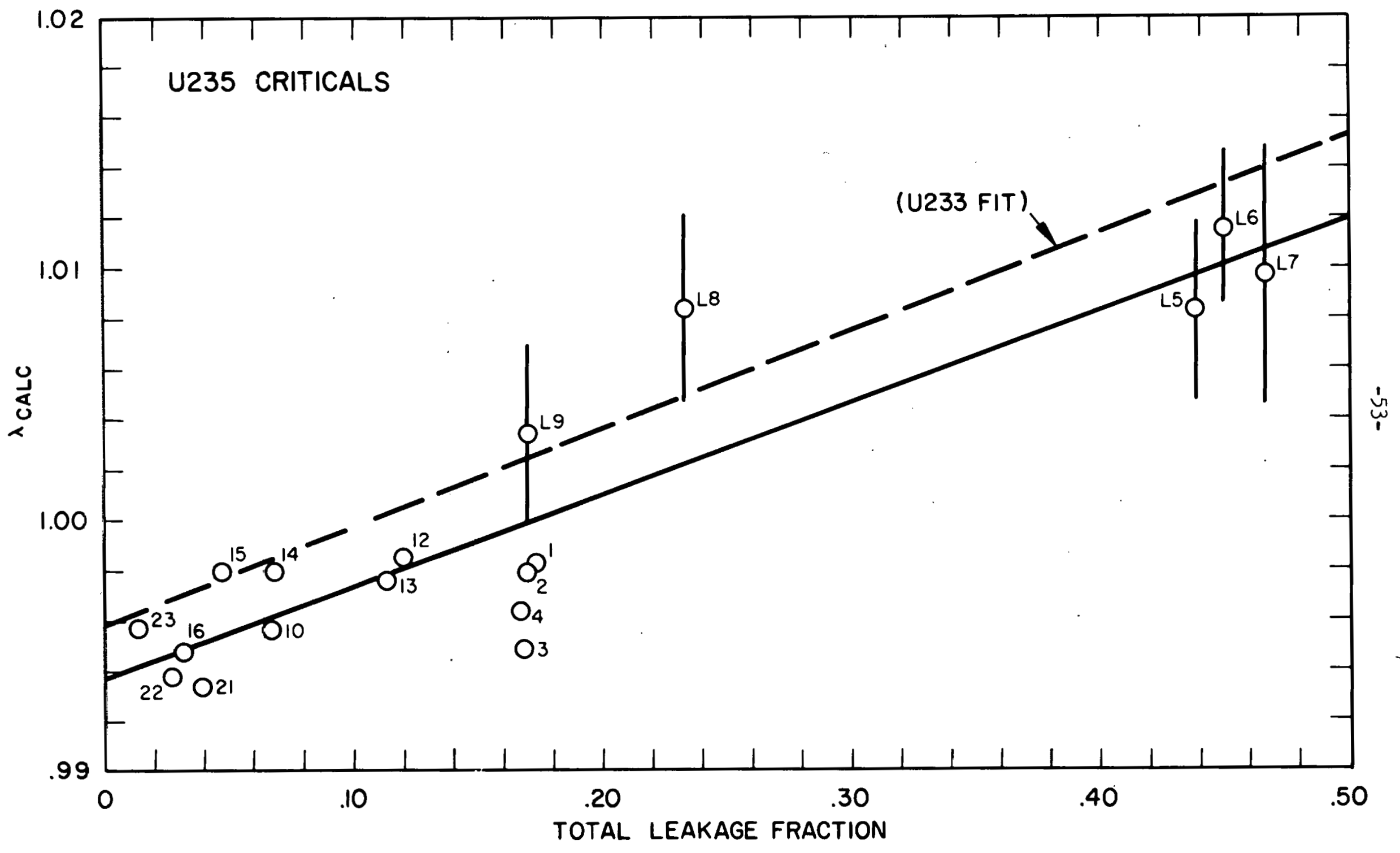

Calculated Eigenvalue Versus Total Leakage Fraction for U235 Criticals

FIGURE 14 


\section{TABLE 17}

Comparison of RCPOl and PTMG Eigenvalue Results

\begin{tabular}{|c|c|c|c|c|}
\hline \multicolumn{2}{|c|}{ Experiment } & \multirow{2}{*}{$\frac{\mathrm{RCPO1} \pm 20)}{0.9969 \pm .0015}$} & \multirow{2}{*}{$\frac{\text { PTNO }}{0.9983}$} & \multirow{2}{*}{$\frac{\text { PTMG/RCPOI }( \pm 20}{1.0014 \pm .0015}$} \\
\hline 0235 & 1 & & & \\
\hline & 16 & $0.9939 \pm .0008$ & 0.9948 & $1.0009 \pm .0008$ \\
\hline & 23 & $0.9949 \pm .0003$ & 0.9957 & $1.0008 \pm .0003$ \\
\hline \multirow[t]{2}{*}{ 0233 } & 5 & $1.0017 \pm .0016$ & 1.0032 & $1.0015 \pm .0016$ \\
\hline & 20 & $0.9956 \pm .0008$ & 0.9967 & $1.0011 \pm .0008$ \\
\hline
\end{tabular}


TABLE 18

\section{Comparison of RCPOI and PTMG Calculated Leakages}

\begin{tabular}{|c|c|c|c|c|}
\hline \multicolumn{2}{|c|}{ Experiment } & $\mathrm{RCPOI}( \pm 0)$ & \multirow{2}{*}{$\frac{\text { PTMG }}{0.1729}$} & RCPOL-PTMG $( \pm \sigma)$ \\
\hline U235 & 1 & $0.1738 \pm .0006$ & & $0.0009 \pm .0006$ \\
\hline & 16 & $0.0329 \pm .0003$ & 0.0321 & $0.0008 \pm .0003$ \\
\hline & 23 & $0.0141+.0001$ & 0.0134 & $0.0007 \pm .0001$ \\
\hline U233 & 5 & $0.1776 \pm .0006$ & 0.1769 & $0.0007 \pm .0006$ \\
\hline & 20 & $0.0402 \pm .0003$ & 0.0398 & $0.0004 \pm .0003$ \\
\hline
\end{tabular}

NOTE: Statistical uncertainties of RCPOl leakage rates do not include eigenfunction convergence effects. 
C. Thermal Criticality Parameter Constraint

The microscopic criticality balance (which expresses the constraint on fissile thermal parameters) was obtained as follows from edits of the calculated whole-core macroscopic reaction rates (see Tables 15 and 16).

In the actual core, which may not be exactly critical,

$$
\lambda_{\text {exp }}=\frac{\text { Theimal VIBB }+ \text { Ep1 VP10E }}{\text { Source }}
$$

Source $=$ Thermal A Ep1 A + Leakage $=1.0$

Reaction rates are for the whole core and are normalized to one neutron born of fission. In the present calculations "Thermal" means $0-0.625$ eV, "Ep1" means E $>0.625 \mathrm{eV}, \mathrm{A}$ is absorption, Fiss is Pission, and VFiss is neutron production. Leakage refers to all energies incluaing thermal.

Thermal absorption and neutron production can be separated out by casting Eqn. (15) in the rorm

$$
\lambda_{\text {exp }}=\frac{\text { Thermal Viss }}{\text { Thermal. } A}
$$

where

$$
\begin{aligned}
\text { FP } & =\left(1+\frac{\text { Epi VFiss }}{\text { Thermal VFiss }}\right)(\text { Thermal A }) \\
& =\left(1+\frac{\text { Epi VFiss }}{\text { Thermal VFiss }}\right)(1-\text { Epi A - Leakage }) .
\end{aligned}
$$

Multiplication by $\frac{\sigma_{\text {af }} /\left\langle\sigma_{\text {aH }}\right\rangle}{\varphi_{\text {Th }} \vee N_{x}}$ converts the thermal absorption and fission rates to microscopic cross sections (denoted $\bar{\sigma}) \cdot \sigma_{\mathrm{aH}} /\left\langle\sigma_{\mathrm{aH}}\right\rangle$ is the ratio of the $2200 \mathrm{~m} / \mathrm{s}$ absorption cross section for hydrogen to the spectrum-averaged value for the range $0-0.625 \mathrm{eV} . \Phi_{\mathrm{Th}} \mathrm{VN} \mathrm{N}_{x}$ is the volume-energy integrated 
thermal flux times the fissile uranium atomic number density.

Note that $F$ and $P$ are not separately defined in Eqn. (18). The most convenlent definition seems to be the following. Let

$$
\begin{aligned}
& p=1-\text { Epl A } \\
& 6 \equiv 1+\frac{\text { Epl VFIss }}{\text { Thermal VPIss }} \\
& P \equiv 1 \text { - Leakage }
\end{aligned}
$$

Then from Eqn. (18), for small leakage

$$
\begin{aligned}
& F P \approx \epsilon(1-\operatorname{Ep} 1 A) \text { (1-Leakage) } \\
& \approx \in p P \\
& \text { with } F=\varepsilon_{p} .
\end{aligned}
$$

Further separation of the fissile uranium and a.l other thermal absorption leads to the form used by Gwin (Ref. 4):

$$
\bar{\sigma}_{\text {ax }}+\frac{H}{\bar{X}} \bar{\sigma}_{\text {aH }}-v \bar{\sigma}_{\text {fx }} \frac{F P}{\lambda_{\text {exp }}}=\bar{\eta}_{x} \bar{\sigma}_{\text {ax }} \frac{F P}{\bar{\lambda}_{\exp }}
$$

In this expression $H / X$ is the effective hydrogen/fissile uranium atomic ratio, that is

$$
\frac{H}{X} \bar{\sigma}_{a H}=\frac{N_{H}}{N_{X}} \bar{\sigma}_{\varepsilon H}+\sum_{1 \neq \dot{X}, H} \frac{H_{1}}{N_{X}} \bar{\sigma}_{a 1}
$$

Neglecting for convenlence the small deviations of $\lambda_{\text {exp }}$ from 1.0 , Egn. (24) can be expressed as a constraint on the microscoplc parameters, denoted K2: 


$$
\mathrm{K} 2=\left(\overline{\bar{\eta}}_{\mathrm{x}}-1\right)\left(\frac{\bar{\sigma}_{\mathrm{ax}}}{\overline{\bar{\sigma}}_{\mathrm{aH}}}\right)=\frac{\mathrm{H}}{\bar{X}}+\frac{\overline{\bar{\sigma}}_{\mathrm{f}}}{\overline{\bar{\sigma}}_{\mathrm{aH}}}(1-\mathrm{FP}) .
$$

Gwin determines $K 2$ as the value of $\mathrm{H} / \mathrm{X}$ at $\mathrm{FP}=1.0$, obtained by a least-squares fit to $\mathrm{H} / \mathrm{X}$ vs FP for many cores:

$$
\frac{\mathrm{H}}{\overline{\mathrm{x}}}=\left(\bar{\eta}_{\mathrm{x}} \frac{\bar{\sigma}_{\mathrm{ax}}}{\bar{\sigma}_{\mathrm{aH}}}\right) \mathrm{FP}-\left(\frac{\bar{\sigma}_{a x}}{\bar{\sigma}_{a H}}\right)
$$

At FP $=1 . U$, the süall eplthermal wulllulication jubt compenoater for all leakage and epithermal absorption. In principle, the slope and intercept determine $\bar{\eta}_{x}$ and $\bar{\sigma}_{\mathrm{ax}} / \bar{\sigma}_{\mathrm{aH}}$ separately, but the sensitivity to errors in determining FP is significant since values of FP range only from $0.8-1.0$, and the Intercept at $F P=0$ is relatively distant.

Since, for fixed H/X (1.e. for a particular core), an error in FP is strongly reflected in the estimate of $K 2$

$$
\left(\frac{\mathrm{dKC}}{\mathrm{dFP}}\right)_{H / X}=-\bar{\eta}_{\mathrm{x}} \frac{\bar{\sigma}_{\mathrm{ax}}}{\bar{\sigma}_{\mathrm{aH}}},
$$

it seems useful to display $K 2$ estimates vs FP. Any drift in $K 2$ - equivalent to a drift in $\lambda$-is evidence of wrong determination of FP and hence of the slope $\bar{\pi}_{x}\left(\bar{\sigma}_{\mathrm{ax}} / \overline{\mathrm{U}}_{\mathrm{aH}}\right)$. At the very leust, liest sluuld ve ho visible drift of $K 2$ in an analysis which seeks to extract useful values of slope and intercept. On the other hand, determination of $\mathrm{K} 2$ at the $\mathrm{FP}=1.0$ limit is relatively free from these uncertainties.

Note that in any particular calculation (as in Tables 15 and 16), the analogue of Eqn. (15) is: 


$$
\lambda_{\text {calc }}=\frac{-59-}{\text { Thermal VFiss }} \text { FP }
$$

and

$$
\text { Thermal } A=\frac{\text { Thermal VP188 }}{\lambda^{\prime}} \frac{\text { FP }}{\lambda_{\text {exp }}}
$$

where

$$
\lambda^{\prime}=\frac{\lambda_{\text {calc }}}{\lambda_{\exp }} .
$$

This leads to the analogue of Eqn. (26)

$$
K 2=\left(\frac{\bar{x}}{\lambda^{\prime}}-1\right)\left(\frac{\bar{\sigma}_{\mathrm{ax}}}{\bar{\sigma}_{\mathrm{aH}}}\right)=\frac{\mathrm{H}}{\overline{\mathrm{X}}}+\frac{\overline{\boldsymbol{\sigma}}_{\mathrm{fx}}}{\lambda^{\prime} \bar{\sigma}_{\mathrm{aH}}}\left(1-\frac{\mathrm{FP}}{\lambda_{\exp }}\right)
$$

and $K 2$ can be obtained from the calculated quantities on elther side of the equation.

The calculated "g-factors" shown in Table 19 are by definition $\bar{\sigma} / \dot{\sigma}(.0253 \mathrm{eV})$. These are significantly smaller than the usual thermal Maxwellian g-factors*, and in fact show a slight variation over the range of $H / X$ spanned by these criticals. Values of $g_{a}$ and $g_{p}$ at the limit $F P=1.0$, suitable for use in applying the constraint to the $2200 \mathrm{~m} / \mathrm{s}$ normalization, are also shown in Table 19. Note that therinal spectrum averages in these calculations are over the flux spectrum from $0-0.625 \mathrm{eV}$.

\footnotetext{
*At the pre-Version IV thermal data task force meeting, only the elgenvalues from the calculations were used. Thermal Maxwellian g-factora were used to derive the constraint $\mathrm{KI}$ ( $=\mathrm{K} 2 \times \bar{\sigma}_{\mathrm{aH}}$ ), and presumably these same g-factors were used in applying the constraint. In any case, this seems to be the reason for the high $K I$ values about which Gwin comments (Ref. 4).
} 
TABLE 19

Additional Calculated Results ${ }^{\dagger}$

\begin{tabular}{|c|c|c|c|c|c|c|c|}
\hline \multicolumn{2}{|c|}{ Experiment } & \multirow[b]{2}{*}{$\begin{array}{c}\mathbf{g}_{\mathbf{a}} \\
.97196 \\
.97093 \\
.96996 \\
.96949 \\
.97286 \\
.97249 \\
.97252 \\
.97284 \\
.41246 \\
.97306 \\
.97302 \\
.97309 \\
.97316\end{array}$} & \multirow{2}{*}{$\begin{array}{l}\mathrm{g}_{\mathrm{f}} \\
.96921 \\
.96808 \\
.96699 \\
.96646 \\
.97022 \\
.96981 \\
.96981 \\
.97020\end{array}$} & \multirow{2}{*}{$\begin{array}{l}\mathrm{H} / \mathrm{x} \\
1404.1 \\
1414.0 \\
1430.3 \\
1427.4 \\
1856.7 \\
1625.7 \\
1658.2 \\
1843.9\end{array}$} & $\begin{array}{l}\text { FP } \\
.8221 \\
.8247 \\
.8265 \\
.8272\end{array}$ & $\begin{array}{c}\mathrm{K} 2 \\
2140.8 \\
2139.3 \\
2149.4 \\
2142.2\end{array}$ & $c^{\prime}$ \\
\hline U235 & $\begin{array}{l}1 \\
2 * \\
3 * \\
4 * \\
10 \\
12 \\
13 \\
14 \\
15 \\
16 \\
21 \\
22 \\
23\end{array}$ & & & & $\begin{array}{l}.8221 \\
.8247 \\
.8265 \\
.8272 \\
.9284 \\
.8754 \\
.8825 \\
.9275 \\
.9480 \\
.9634 \\
.9566 \\
.9686 \\
.9821\end{array}$ & $\begin{array}{l}2140.8 \\
2139.3 \\
2149.4 \\
2142.2 \\
2154.3 \\
2141.6 \\
214.5 .3 \\
2144.4 \\
21.4 .4 .9 \\
2158.4 \\
2164.3 \\
2162.5 \\
2154.8\end{array}$ & $\begin{array}{r}736.7 \\
725.3 \\
719.1 \\
714.8 \\
297.6 \\
515.4 \\
487.1 \\
300.5 \\
215.6 \\
152.2 \\
180.8 \\
130.8 \\
74.6\end{array}$ \\
\hline & $\#$ & .97326 & .97065 & & 1.0 & & \\
\hline U233 & $\begin{array}{l}5 \\
6 * \\
7 * \\
8 * \\
9 * \\
11 \\
17 \\
18 \\
19 \\
20\end{array}$ & $\begin{array}{l}1.00072 \\
1.00079 \\
1.00085 \\
1.00092 \\
1.00090 \\
1.00052 \\
1.00058 \\
1.00055 \\
1.00052 \\
1.00049\end{array}$ & $\begin{array}{l}.99771 \\
.99775 \\
.99780 \\
.99784 \\
.99700 \\
.99750 \\
.99762 \\
.99759 \\
.99757 \\
.99755\end{array}$ & $\begin{array}{l}1554.9 \\
1559.3 \\
1565.4 \\
1570.9 \\
1577.7 \\
2005.0 \\
1839.2 \\
1920.3 \\
2017.0 \\
2127.0\end{array}$ & $\begin{array}{l}.8334 \\
.8349 \\
.8363 \\
.8376 \\
.0309 \\
.9433 \\
.9018 \\
.9235 \\
.9470 \\
.9725\end{array}$ & $\begin{array}{l}2210.0 \\
2208.0 \\
2208.7 \\
2209.2 \\
2211.5 \\
2229.2 \\
2226.8 \\
2221.9 \\
2226.3 \\
2235.8\end{array}$ & $\begin{array}{l}655.1 \\
648.7 \\
643.3 \\
638.3 \\
633.8 \\
224.2 \\
387.6 \\
301.6 \\
209.3 \\
108.8\end{array}$ \\
\hline & $\#$ & 1.00045 & .99752 & & 1.0 & & \\
\hline
\end{tabular}

*Boron loeded.

${ }^{\dagger}$ See text for definitions of $\mathrm{g}_{\mathrm{a}}, \mathrm{g}_{\mathrm{f}}, \mathrm{H} / \mathrm{X}, \mathrm{FP}$ and $\mathrm{K} 2$.

$$
C^{\prime}=\frac{v \bar{\sigma}_{f x}}{\lambda^{\prime} \bar{\sigma}_{a H}}
$$

\#The values of $g_{a}$ and $g_{f}$ at $F P=1.0$ have been obtained by extrapolation. 
12 values, calculated for each core from Eqn. (31), are shown in Table 19 and In Figures 15 and 16. Table 20 shows the limiting values of $K 2$ at FP= 1.0 obtained from a least squares fit for various assumptions. For comparison, the same quantity 'obtained from a fit to Eqn. (27) is also shown. Differences between these two estimates are small.

The uncertainties shown for $K 2$ estimates of Table 20 are standard deviations obtained from the least squares fit. They reflect only the scatter of K2 values (in Figure 15 for example) wich is attributed to experimental fissile loading uncertaintles. It is noteworthy that eigenvalues of the 0233 criticals exhibit much less scatter than do those of the Ue35 criticals.

For U235 systems there is a significant difference in $K 2$ (at $F P=1.0$ ) depending on whether or not the three tubs (Experiments 21, 22, 23) are included in the fit: Including the tubs raises $\mathrm{K} 2$ by $0.26 \%$. Whether or not the boron loaded cores are Included has little effect.

The nonconstancy of the K2 estimates with FP is due to the underprediction of leakage. To assess the effect of this leakage error on the IImiting value of $\mathrm{K} 2$, a second series of calculations was done with fast leakage enhanced artificially by hardening the fission spectrum (a Maxwellian with $\overline{\mathrm{E}}=2.1 \mathrm{MeV}$ was used). These results are shown in Figures 15 and 17 and in Table 20. The calculations with enhanced leakage produce only small differences in the estimate of $\mathrm{K2}$ at FP $=1.0$. It should be noted that the device used (hardening the fission spectrum) produces a small residual eigenvalue difference in addition to the main effect, the increase of leakage. 
$-62-$

TABLE 20

Estimates of $\mathrm{K} 2$ at $\mathrm{FP}=1.0$

Experiments From Eqn. 27 From K2 vs FP $\begin{gathered}\text { From K2 vs FP } \\ \text { (enhanced leakage) }\end{gathered}$

U235 All $2158.6 \pm 3.1 \quad 2159.5 \pm 3.3 \quad 2160.9 \pm 3.5$

Omit $2,3,4 \quad 2160.1 \pm 3.7 \quad 2161.0 \pm 4.0 \quad 2162.6 \pm 4.3$

omit $21,22,23 \quad 2153.4 \pm 3.8 \quad 2154.4 \pm 4.5 \quad 2155.4 \pm 4.8$

UR33 AlI $2237.4 \pm 2.2 \quad 2238.9 \pm 2.5 \quad 2242.3 \pm 2.3$

Omit $6,7,8,9 \quad 2236.9 \pm 3.8 \quad 2238.1 \pm 4.3 \quad 2241.7 \pm 4.3$

Note: Uncertainties are standard deviations obtained from the least squares fit.

$K 2=\left(\bar{\eta}_{x}-1\right)\left(\frac{\bar{\sigma}_{\text {ax }}}{\bar{\sigma}_{\mathrm{aH}}}\right)$

See Eqn. 19 for definition of FP.

Experiments 2, 3, 4 and 6, 7, 8, 9 are boron loaded.

Experiments $21,22,23$ are the large tubs. 


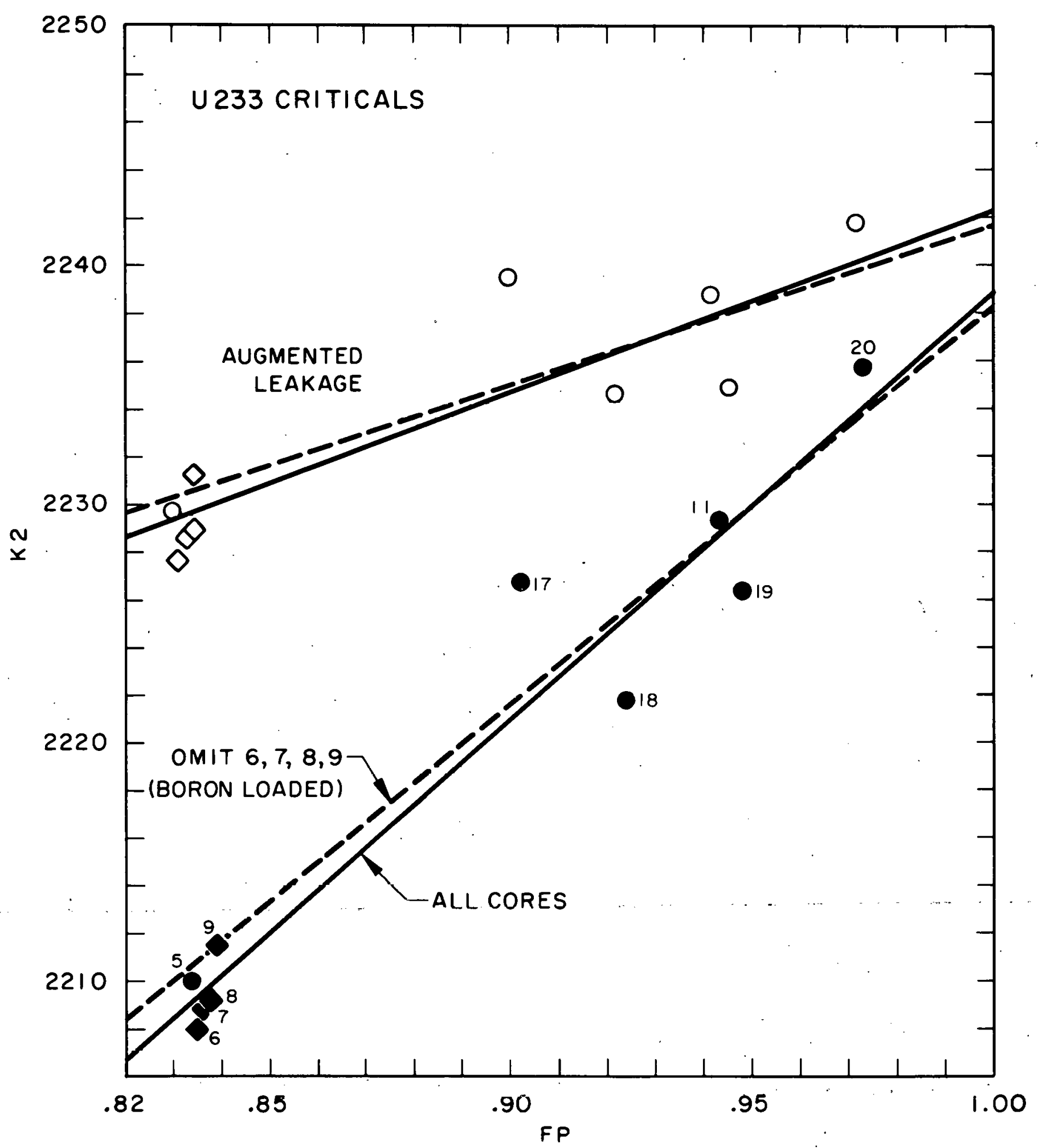

Thermal Criticality Parameter Ké Versus FP, Calculated with ENDF/B-IV and with Augmented Leakage for Ue33 Crivirals

FIGURE 13 


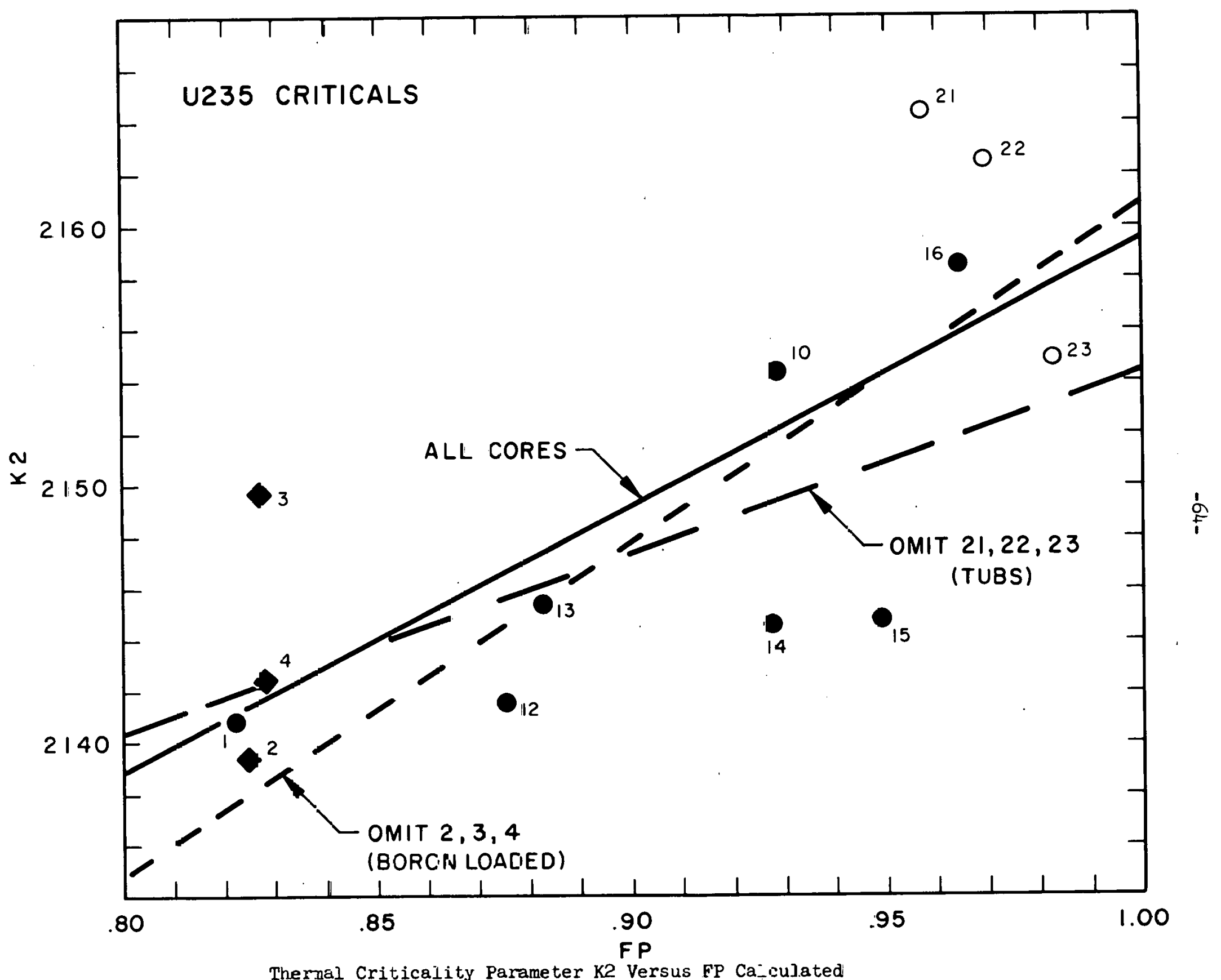

Thernal Criticality Parameter $\mathrm{K} 2$ Versus FP Ca-culated with ENDF/B-IV for U235 Criticals 


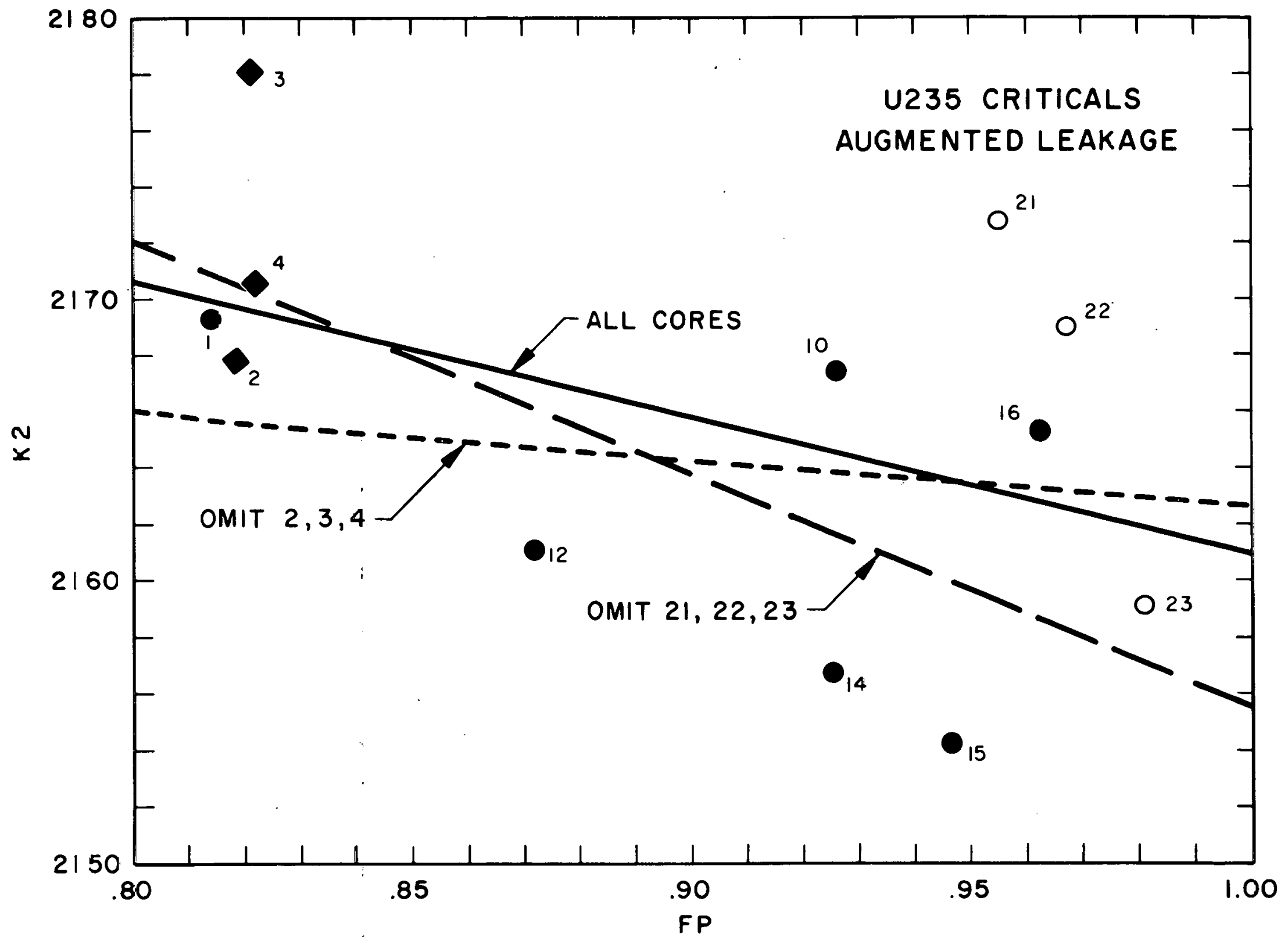

Thermal Criticality Parameter $\mathrm{K} 2$ Versus FP Calculated with Augmented Leakage for U235 Criticals

FIGURE 17 
The best $\mathrm{k} 2$ values to be derlved from this analysis are taken to be:

$$
\begin{array}{ll}
\text { U233 } & 2240 \pm 11(0.5 \% \sigma) \\
\text { v235 } & 2155 \pm 11(0.5 \% \sigma)
\end{array}
$$

These are somewhat higher than values derived by Gwin (Ref. 4), which are shown in Table 21.

An overall uncertainty of \pm 11 units $(0.3 \%)$ häs been assigned to $\mathrm{K} 2$ based on consideration of the items summarlzed in Table 22 . A detailed discussion of these factors is given in Appendix $I$.

The U235 tubs have been omitted from the fit and the uncertainty chosen large enough to include them. Although no specific reasons can be cited for this choice, it is felt that the tubs are slightly less well understood than the spheres and cylinders (for example, no experimental support-structure correction was applied) and they were measured in a different facility. Also, consistency with the 0233 results may be improved by this choice, since there were no Ve33 tubs.

Since for all practical purposes the derlved value of $K 2$ is independent of the value taken for $\sigma_{\mathrm{aH}}$ (see P-ppendix II) and $K I=K 2 \times \bar{\sigma}_{\text {aH }}$, two major alternatives in the least squares adjustment are:

(1) Let $\sigma_{a H}$ be adjustable, using the constraints

$$
\left(\bar{\eta}_{x}-1\right) \frac{\bar{\sigma}_{\mathrm{ax}}}{\sigma_{\mathrm{aH}}}=\mathrm{K} 2 \pm \sigma_{\mathrm{KL}}
$$


$-67-$

TABLE 21

Values of K2 at FP $=1.0$ Derived by Gwin (Ref. 4) with Meesured Bucklings

$\begin{array}{ccc}\text { Fast B } & \frac{\text { U233 }}{2237} & \frac{\text { U235 }}{2150} \\ \text { Thermal } B^{2} & \underline{2231} & \underline{2145} \\ \text { AVERAGE } & 2234 & 2148\end{array}$


$-68-$

TABLE 22

Factors Considered in Assigning Uncertainty to KR

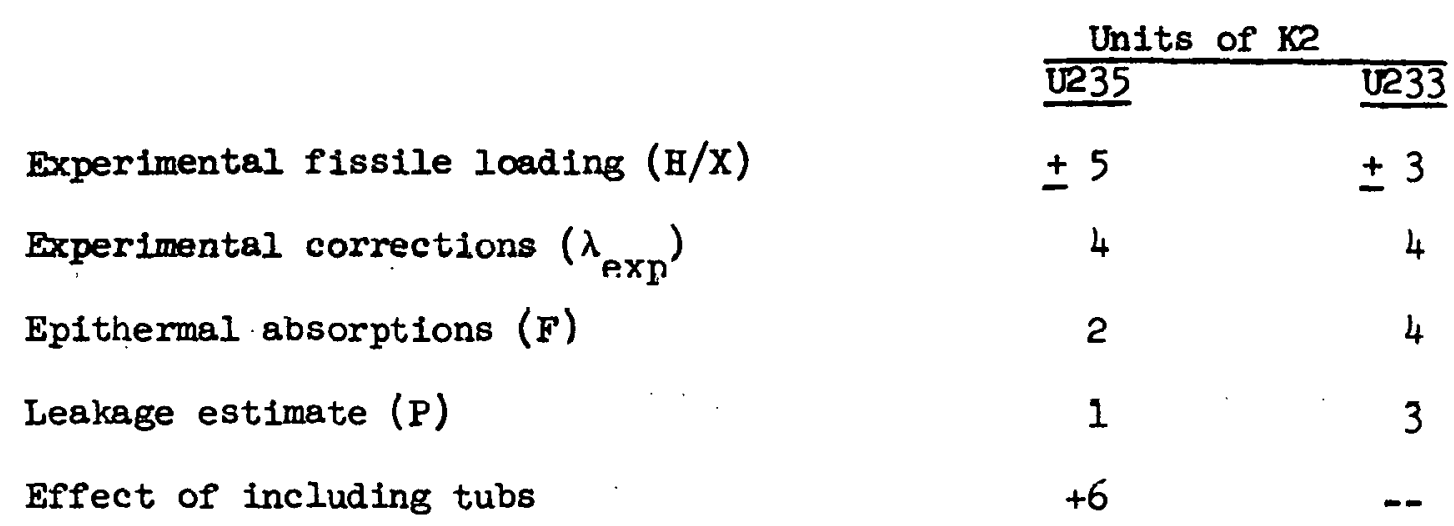


and

$$
\sigma_{\mathrm{aH}}=.332 \pm .002(0.6 \%)
$$

plus calculated "g-factors" (Table 19).

(2) Let $\sigma_{\text {aH }}$ be held fixed, using the constraint

$$
\left(\bar{\eta}_{\mathrm{x}}-1\right) \cdot \bar{\sigma}_{\mathrm{ax}}=\mathrm{Kl} \pm{ }^{6 \mathrm{Kl}}
$$

where

$$
\mathrm{Kl}=\mathrm{KL} \times \overline{\bar{\sigma}}_{\mathrm{aH}}
$$

plus calculated "g-factors" (Table 19).

The uncertainty on the fissile parameter constraint $K \perp\left(\bar{\eta}_{x}-1\right) \bar{\sigma}_{a x}$ 1s dominated by the uncertainty of $\sigma_{\mathrm{aH}}(.0253 \mathrm{eV})$. That is

$$
\left(\frac{\delta K I}{K I}\right)^{2}=\left(\frac{\delta K 2}{K 2}\right)^{2}+\left(\frac{\delta \sigma_{\mathrm{aH}}}{\sigma_{\mathrm{aH}}}\right)^{2}
$$

A $0.5 \%$ uncertainty on $\mathrm{K} 2$ and $0.6 \%$ on $\sigma_{\mathrm{aH}}$, implies $0.8 \%$ uncertainty on KI*. It should be noted that the value and uncertainty adopted for $\sigma_{\text {aH }}$ are somewhat "conventional" and might well be re-examined.

In a previous analysis of the U235 spheres (done in connection with EHVF/B-IV preparation), an uncertainty on $\lambda_{\text {calc }}$ of $0.4 \%$ was chosen. This implies an uncertainty of $\sim 0.8 \%$ on $\mathrm{KI}$. 


\section{ACKNOWLEDGMENTS}

The authors wish to thank Francis Perey and Reggie Gwin of Oak Ridge National Iaburatory for valuable discussions and comments, and Herbert Henryson II (Argonne National Laboratory) for providing the VIM calculational results. Thanks for great dedication are due to Stella Dokish and Deboralı Iannuzzi for performing the calculations and to sie carr for the lyplus. 


\section{REFERENCES}

1. S. R. McNeany and J. D. Jenkins, "Comparison of Hanson-Roach and ENDF/B-IV Cross Sections for ${ }^{233}$ U Criticality Calculations," ORNL-TM5113, Oak Ridge National Laboratory (1976).

2. R. Gwin and D. W. Magnuson, Nucl. Sci. Eng., 12, 364 (1962).

3. Cross Section Evaluation Working Group Benchmark Specifications, ENDF-202, November 1974.

4. R. Gwin, "Critical Experiments and the $2200 \mathrm{~m} / \mathrm{s}$ Neutron Parameters," ORNL-TM-4550, January 1975.

5. G. H. Conley, "A Pattern in Monte Carlo Calculations of Critical Experiments," Transactions of the A.N.S., Vol. 11, No. 1, p. 160, June 1968.

6. D. E. Kusner, S. Kellman, and R. A. Dannels, "ETOG-I, A Fortran IV Program to Process Data from the ENDF/B File to the MUFT, GAM, and ANISN Formats," WCAP-3845-1 (ENDF 114), December 1969.

7. C. L. Beard and R. A. Dannels, "ET $\phi$ T, A Fortran IV Program to Process Data from the ENDF/B File to Thermal Library Format," WCAP-7363, March 1971.

8. H. C. Honeck and D. R. Finch, "FLANGEII (Version 71-1). A Code to Process Thermal Neutron Data from an ENDF/B Tape," DP-1278, October 1971.

9. N. R. Candelore and R. C. Gast, "RECAP-3, A Monte Carlo Program for Estimating Epithermal Capture Rates in Rectangular or $60^{\circ}$ Parallelogram Geometry," WAPD-TM-437, 1964.

10. H. Bohl, Jr., et al., "P3MG-1, A One-Dimensional Multigroup P-3 Program for the Philco-2000 Computer," WAPD-TM-272, 1963. 
11. A. Staub, et al., Nuclear Sci. Eng. 34, 263 (1968).

12. J. T. Thomas, "Critical Experiments with Aqueous Solutions of ${ }^{233} \mathrm{UO}_{2}\left(\mathrm{NO}_{3}\right)_{2}$," in "Neutron Physics Division Annaal Progress Report for Period Ending May 31, 1968," ORNL-4280, Oak Ridge National Laboratory.

13. J. K. Fox, L. W. Gilley, and E. R. Rohrer, "Critical Mass Studies, Part VIII, Aqueous Solutions of ${ }^{233} \mathrm{U}, "$ OKNL-2143 (1959).

14. J. K. Fax, L. W. Gilley, and D. Callihan, "Critical Mass Studies, Part IX, Aqueous نें3 Solutions," ORNL-2367, 22 (1958).

15. J. K. Fox, L. W. Gilley, R. Gwin, and J. T. Thomas, "Critical Parameters of Uranium Solutions in Simple Geometry," In "Neutron Physics Division Annual Progress Report for Perlod Ending September 1, 1958," ORIL-2609, Oak Ridge National Laboratory (1958).

16. E. M. Gelbard and R. E. Prael, "Monte Carlo Work at Argonne National Laboratory," Proc. NEACRP Meeting of a Monte Carlo Study Group, July 1-3, 1974, ANL-75-2 (NEA-CRP-118), Argonne National Laboratory (1975), p. 201 .

17. P. I. Johansson et al., Conference on Nuclear Cross Sections and Technology, Washington, D.C. 1975, NBS Special Publication 425, 572.

18. N. M. Steen, "Analysis of the Fission Neutron Spectrum of Uranium-233 and Criticality Computations for Homogeneous Uranium-233- $\mathrm{I}_{2} \mathrm{O}$ spheres and Cylinders," WAPD-TM-997, Bettis Atomic Power Laboratory (1972).

19. S. F. Maghabghab and D. I. Garber, "Neutron Cross Sections," BNL-325, Third Edition, June 1973. 


\section{APPENDIX I}

Uncertainty of K2 Estimste

The components of uncertainty in the estimate of $\mathrm{K} 2$ can be seen from Eqn. 31:

$$
K 2=\frac{H}{X}+c^{\prime}\left(1-\frac{F P}{\lambda_{\exp }}\right)
$$

where

$$
c^{\prime} \equiv \frac{\bar{w}_{f x}}{\lambda^{\prime} \bar{\sigma}_{\text {aH }}} \approx 4000 \text { (for both U233 and U235) }
$$

Now,

$$
\delta(K 2)=\delta(H / X)+\left(\delta c^{\prime}\right)\left(1-\frac{F P}{\lambda_{\text {exp }}}\right)+c^{\prime} \delta\left(1-\frac{F P}{\lambda_{\text {exp }}}\right)
$$

Near $\frac{F P}{\lambda_{\exp }}=1.0$,

$$
\begin{aligned}
\sigma(K 2) & =\delta(H / X)+c^{\prime} \delta\left(1-\frac{F P}{\lambda_{\text {exp }}}\right) \\
& =\delta(H / X)-c^{\prime} \cdot \delta\left(\frac{F P}{\lambda_{\text {exp }}}\right) \frac{\text { FP }}{\lambda_{\text {exp }}}=1.0
\end{aligned}
$$

The term $\sigma(B / X)$ is dominated by the experimental loading uncertainty (from the least squares fit, Table 20). The calculation itself contributes negligible uncertainty here, and no account is taken of any possible systematic error in loading determination.

The slgnificant calculational uncertainties enter through 


$$
\left[\delta\left(\frac{F P}{\lambda_{\exp }}\right)\right]_{\frac{F P}{\lambda_{\exp }}}^{I-2}=1.0
$$

(1) An uncertaincy of $0.1 \%$ is assigned to $\lambda_{\text {exp }}$ to account for experimental effects other than fissile inventory. Corrections (Ref. 2,11) to $\lambda_{\exp }$ accounting for such things as room return and support structure are relatively small. The room return correction (Ref. 1l) is approximately -.0003 for all cores, but this could be doubled under different assumptions (Ref. 18). The net correction (Ref. il) for all effects (for the spheres) is approximately -.001 .

(2) Uncertainty of $F$ is estimated as follows. From Eqn. (23):

$$
\begin{aligned}
F & \approx\left(1+\frac{\text { Epi UFiss }}{\text { Ther } V F i s s}\right)(1-\text { Epi } \Lambda) \\
\text { F-I } & \approx \text { Epi UFiss - Epi } A \\
& \approx(\nu-1) \text { Epi Fiss - Epi } C_{x}-\text { Epi } A_{H}-\text { Epi } A_{O}
\end{aligned}
$$

where the terms represent fission, uranium capture, hydrogen absorption and oxygen absorption respectively. Other epithermal absorption is negligible.

$$
\begin{aligned}
\delta F & =\delta(F-1) r(v-1) \delta(\text { EpI Fiss })+(\text { Epl Flss }) \delta(v-1) \\
& -\delta\left(\text { Epi } C_{x}\right)-\delta\left(\text { Epi } A_{H}\right)-\delta\left(\text { Epi } A_{0}\right) .
\end{aligned}
$$


Table AI-l shows the isotopic epithermal absorption rates for representative experiments (20 and 23). Aside from uranium, only hydrogen and oxygen are important. At this dilution, epithermal reaction rate uncertainties should be dominated by uncertainties of the absorption and fission ("resonance") integrals. Evaluation of the terms in Eqn. (I-5) is summarized in Table I-2. Depending on correlations, the net uncertainty of F 18 less than $0.1 \%$ and likely to be $.05 \%$ for U235. For U233 these uncertainties are doubled due to the significantly larger epithermal fission integral. Values of . $.05 \%$ and $0.1 \%$ respectively are chosen. With $C^{\prime}=4000$, these contribute 2 and 4 units to the uncertainty of $\mathrm{K} 2$.

(3). Errors steming from the leakage calculation ( via P) are relatively small at, $F P=1.0$. The enhanced fast leakage calculation (Table 20) increased the K2 estimate by about 1.0 unit for U235 and 3 units for U233. 


$$
I-4
$$

TABLE I-1

\section{Epithermal Absorption Rates}

$\begin{array}{lcc}\text { U235Fiss } & \frac{\text { Exp. } 23}{.00667} & \frac{\text { Exp. } 20}{\text { Cap }} \\ \text { U233Fiss } & .00321 & - \\ \text { Cap } & -- & .01756 \\ \text { H } & -- & .00310 \\ 0 & .00670 & .00652 \\ \text { U234 } & .00317 & .00314 \\ \text { U236 } & .00017 & .00022 \\ \text { U238 } & .00006 & -- \\ \text { N } & .00038 & .00007 \\ \text { TOTAL } & .00023 & .00014 \\ & & .03075\end{array}$


TABLE I-2

\section{Factors Contributing to Uncertainty of $F$}

\begin{tabular}{|c|c|c|c|c|}
\hline \multirow{3}{*}{$\frac{\operatorname{Term} \text { (Eqn. I-5) }}{(v-I) \delta(\text { Bpi Fiss) }}$} & \multirow{2}{*}{\multicolumn{2}{|c|}{$\begin{array}{c}\text { Assigned } \\
\text { Uncertainty }\end{array}$}} & \multicolumn{2}{|c|}{ Contribution to $\delta \mathrm{F}$} \\
\hline & & & Exp. 23 & Bxp. 20 \\
\hline & U235 & $1.8 \%$ & .00017 & - \\
\hline & U233 & $1.7 \%$ & - & .00045 \\
\hline$(E p 1 F 188) \&(v-1)$ & $2 \%$ on & & .00033 & -- \\
\hline & & & - & .00087 \\
\hline$s\left(\right.$ Epi $\left.C_{x}\right)$ & v235 & $4.2 \%$ & .00013 & - \\
\hline & U233 & $4.3 \%$ & - & .00013 \\
\hline $8\left(\begin{array}{lll}E_{0} & A_{H}\end{array}\right)$ & $1 \%$ & & .00007 & .00007 \\
\hline 8 (Epi $\left.A_{0}\right)$ & $5 \%$ & & .00016 & .00016 \\
\hline Total (u & orrelat & & .00043 & .00100 \\
\hline & (additi & & .00086 & .00168 \\
\hline
\end{tabular}

NOTE: Uranium capture and fiseion integral uncextainties are taken from Ref. 19. 
II-1

APPENDIX II

Sensitivity of $\mathrm{K} 2$ to $\sigma_{\mathrm{aH}}(.0253 \mathrm{eV})$

For practical purposes, the estimate of $\mathrm{K}$ at $\mathrm{FP}=1.0$ is independent of the choice of $\sigma_{\mathrm{aH}}(.0253 \mathrm{eV})$. This was verified by repeating the entire analysis with $\sigma_{\mathrm{aH}}(.0253 \mathrm{eV})=0.330 \mathrm{~b}$ instead of $0.332 \mathrm{~b}$. Results are shown in Table II-I.

\section{TABLE II-I}

Sensitivity of $\mathrm{KQ}(\mathrm{FP}=1.0)$ to Choice of $\sigma_{\mathrm{QH}}(.0253 \mathrm{eV})$

$\underline{\sigma_{\mathrm{aH}}(.0253 \mathrm{eV})}$

$0.332 \mathrm{~b}$

$0.330 \mathrm{~b}$

\begin{tabular}{|c|c|}
\hline U233 & U235 \\
\hline 2236.1 & 2159.1 \\
\hline 2237.0 & 2159.7 \\
\hline
\end{tabular}

Details of the sensitivity can be seen from the expression (Ref. 4):

$$
\mathrm{K}=\frac{\mathrm{H}}{\mathrm{x}} \bar{\sigma}_{\mathrm{aH}}+\frac{\bar{\nu}_{\mathrm{fx}}}{\lambda^{\prime}}(1-\mathrm{FP})=\frac{\mathrm{H}}{\mathrm{x}} \bar{\sigma}_{\mathrm{aH}}+\mathrm{c}
$$

and from Table II-2 which shows the component parts of $K$ for two extreme cases (Experiments 1 and 23).

$H / X$ and $\bar{w}_{f x}$ are essentially unchanged and $c$ shows relatively small change, stemming from small changes of $\lambda^{\prime}$ and l-FP which nearly cancel. For large cores, where $c$ is relatively unimportant, the $0.6 \%$ reduction of $\bar{\sigma}_{\text {aH }}$ causes nearly a $0.6 \%$ reduction of $K \mathrm{~K}$ and no change of $\mathrm{K} 2=\frac{\mathrm{K}}{\bar{\sigma}_{\mathrm{aH}}}$. For the leakier cores, where $c$ is $25 \%$ of $K$, there is a $0.45 \%$ reduction of $K$ and $0.15 \%$ increase of $K 2$. 
Since $K 2$ is independent of $\sigma_{\mathrm{aH}}$ for the large cores and slightly dependent for the smaller cores, one might in principle use consistency of the $K 2$ estimate over all cores to determine a best $\sigma_{\mathrm{aH}}$. Unfortunately, the small variation is overwhelmed by uncertainty of the leakage calculation and by experimental scatter. 
II-3

TABLE II-2

Sensitivity of the Constraints to $\sigma_{\mathrm{aH}}(.0253 \mathrm{eV})$

Experiment 1

\begin{tabular}{|c|c|c|c|c|c|c|}
\hline \multirow[b]{2}{*}{$\sigma_{\mathrm{aH}}(\mathrm{b})$} & & \multicolumn{3}{|c|}{$\pi$} \\
\hline & .332 & .330 & $\frac{\text { क Change }}{-.6}$ & .332 & 330 & $\frac{6 \text { Change }}{-.6}$ \\
\hline$\lambda^{\prime}$ & .99829 & 1.00063 & +.23 & .99592 & .99889 & +.30 \\
\hline$H / X$ & 1404.1 & 1404.3 & & 2080.2 & 2080.4 & \\
\hline$v \bar{\sigma}_{f x}$ & 1372.4 & 1372.4 & & 1374.3 & 1374.3 & \\
\hline $1-F P$ & .17794 & .17803 & & .01775 & .01780 & \\
\hline C & 244.6 & 244.2 & & 24.5 & 24.5 & \\
\hline Ke & 2140.9 & 2144.2 & +.15 & 2154.0 & 2154.6 & +.03 \\
\hline $\mathbf{K}$ & 710.8 & 707.6 & -.45 & 715.1 & 711.0 & -.57 \\
\hline
\end{tabular}

NOTE: These values are from preliminary calculations. 